\title{
Microtechnological Tools to Achieve Sustainable Food Processes, Products, and Ingredients
}

\author{
Karin Schroën $^{1,2}$ (D) Jolet de Ruiter ${ }^{1}$ - Claire C. Berton-Carabin ${ }^{1}$
}

Received: 21 December 2019 / Accepted: 19 February 2020 / Published online: 17 March 2020

(C) The Author(s) 2020

\begin{abstract}
One of the major challenges we face as humankind is supplying a growing world population with sufficient and healthy foods. Although from a worldwide perspective sufficient food is produced, locally, the situation can be dire. Furthermore, the production needs to be increased in a sustainable manner for future generations, which also implies prevention of food waste, and making better use of the available resources. How to contribute to this as food technologists is an ultimate question, especially since the tools that can investigate processes at relevant time scales, and dimensions, are lacking. Here we propose the use of microtechnology and show examples of how this has led to new insights in the fields of ingredient isolation (filtration), and emulsion/foam formation, which will ultimately lead to better-defined products. Furthermore, microfluidic tools have been applied for testing ingredient functionality, and for this, various examples are discussed that will expectedly contribute to making better use of more sustainably sourced starting materials (e.g., novel protein sources). This review will wrap up with a section in which we discuss future developments. We expect that it will be possible to link food properties to the effects that foods create in vivo. We thus expand the scope of this review that is technical in nature, toward physiological functionality, and ultimately to rational food design that is targeted to improve human health.
\end{abstract}

Keywords Sustainable food design · Filtration · Ingredient fractionation · Microfluidics · Microtechnology $\cdot$ Emulsification · Functionality testing · Sensors · Organs on chip · Protein transition

\section{Introduction}

The sustainable development goals of the United Nations revolve in many ways around food-related issues, extending from prevention of poverty all the way to partnerships to achieve the defined goals (Fig. 1). Food is obviously related to the goal to reach zero hunger, but also all other goals are strongly related to food and its current production methods, accessibility, and future developments to achieve sustainability for future generations. For the food field, this is in essence a good position to be in, but at the same time also a position that comes with responsibility, especially since the UN has

Karin Schroën

karin.schroen@wur.nl; c.g.p.h.schroen@utwente.nl

1 Department of Agrotechnology \& Food Sciences, Laboratory of Food Process Engineering Group, Wageningen University, Bornse Weilanden 9, 6708 WG Wageningen, The Netherlands

2 Faculty of Science and Technology, Membrane Processes for Food, University of Twente, Enschede, The Netherlands reported in August 2019 that food shortages are expected to occur from 2050 onward.

It would lead too far to go into all the 17 goals and point out where food technologists could contribute; therefore, this review limits itself to the technical production of food and food ingredients. Although food is produced at huge scale worldwide, we feel that essential improvements are possible if we would be able to bridge the gap between the scales at which we design foods and make foods. A food designer thinks in terms of ingredients, so on a molecular scale, while a food process engineer would typically think in terms of cubic meter. Many scales in between are essential for preparation of the smallest food structures, and separation of raw materials, but these are often disregarded because of the lack of appropriate tools to measure effects that take place very fast and at small scale. It is simply difficult to assess the determining mechanisms because they typically take place at micro/nanometer level and within (sub-)milliseconds, and highly dedicated equipment is needed.

Within this review, we address two aspects of food production, obtaining ingredients and making food structures in a mild manner. We focus on processes in which liquids are used, 


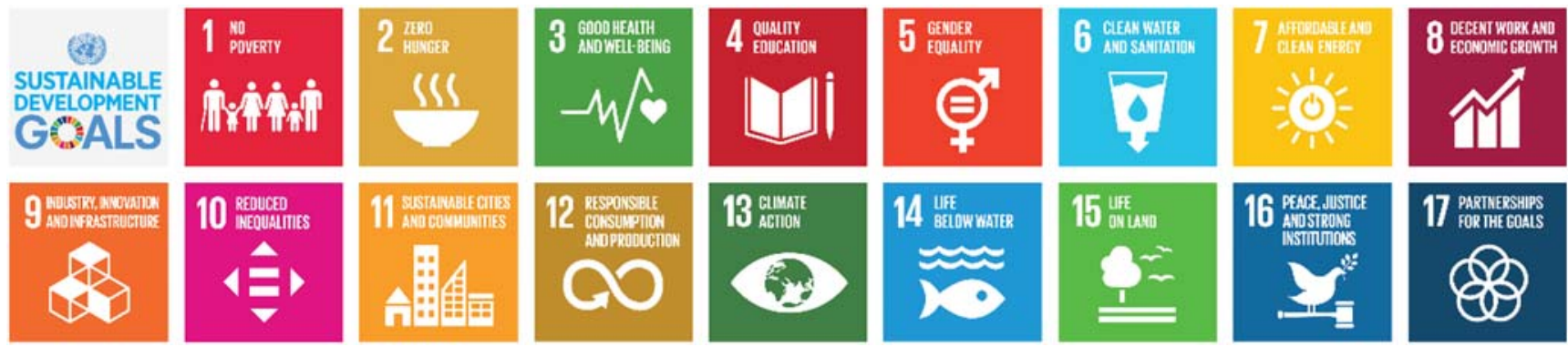

Fig. 1 Graphical representation of the sustainable development goals defined by the United Nations (https://sustainabledevelopment.un.org/)

which are either the final products or an intermediate state of food products (e.g., before drying). We link processes as currently operated to observations done with microfluidic tools. The underlying mechanisms are discussed, and innovative processes are suggested that are relatively low in energy consumption and expected to be less detrimental to ingredient structure. Furthermore, we present a number of tools with which ingredient functionality may be tested, which could be a starting point for rapid identification and characterization of novel ingredients, and thus speeding up food design.

The review wraps up with a section on the use of sensors. This application takes microfluidic tools even one step further, namely for the investigation of interactions of food with digestive liquids and even organs. Organ-on-a-chip approaches are currently being developed for studying human physiology and medical diagnostics. Although it will take time to implement these findings into the field of food design, the time is there to consider them as part of the tools needed to make foods for a sustainable future as pointed out earlier (Fig. 1).

\section{Filtration and Ingredient Fractionation}

In food ingredient production, which nowadays also includes biorefineries, various separation processes are used. Sometimes this revolves around isolation of only one product of interest or removal of a toxic component as would be the case in, for example, chromatography using specific ligands. However, for food production, mostly enrichment of the component of interest suffices. For example, various streams stemming from milk are enriched in the dairy industry. It is convenient to use liquid starting materials as such and apply, for example, membrane filtration to separate them into enriched fractions that then are used in the design of food products. As membrane filtration in general removes solutes from a fluid stream by means of retention based on pore size, membrane separation uses significantly less energy than other separation techniques based on "thermal treatment" (evaporation), phase transitions, or addition of solvents. When the starting material is a solid, it may be favorable to separate directly, e.g., through electrostatic separation. This avoids dilution of the feed that would have resulted in energy-intensive removal of water later on. Still, many materials are in a liquid form when fractionation takes place, and that allows the use of different driving forces, such as an electric field. Very recently, we found that in this way, both protein and salt separation are possible in concurrent mode (unpublished results) using an approach similar to what we used for salt separation [39].

For the current review, we will limit ourselves to standard membrane separation processes that revolve around pressure as the main driving force and will illustrate this using examples from the dairy field. Later we compare this to observations done with microtechnological membranes and give an outlook on what this implies for fractionation of other starting materials, e.g., in terms of the transition toward plant-based proteins that currently is very much in the spotlight. In the next section, a link will be established to the functionality of these novel components and how this can be investigated using microfluidic tools.

\section{Membranes in Food Processing}

Traditionally, milk is separated to produce a wide range of dairy products. Given the size range of typical dairy ingredients, the match with membranes is a logical one to make, as illustrated in Fig. 2.

The pore size of the membrane is normally chosen based on the component of interest, and given the overlapping sizes thereof in Fig. 2, it is also clear that multiple membranes would need to be used in close conjunction to get desired enrichment of components. This is even further hampered by the fact that due to the gate keeper function of the membranes, components are rejected and accumulate on the membrane. This so-called fouling process greatly influences the separation characteristics (yield and flux). Furthermore, commercial membranes have a pore size distribution, which implies that the separation obtained would vary as function of the pore size (within one membrane). Overall, a very complex mirage of effects, that to make matters worse, is influenced by the applied process conditions.

After having mentioned all these effects, one would be very surprised if any successful process based on membranes were possible, but there are many successful examples, also operated at very large scale in the dairy industry. Worldwide, more 

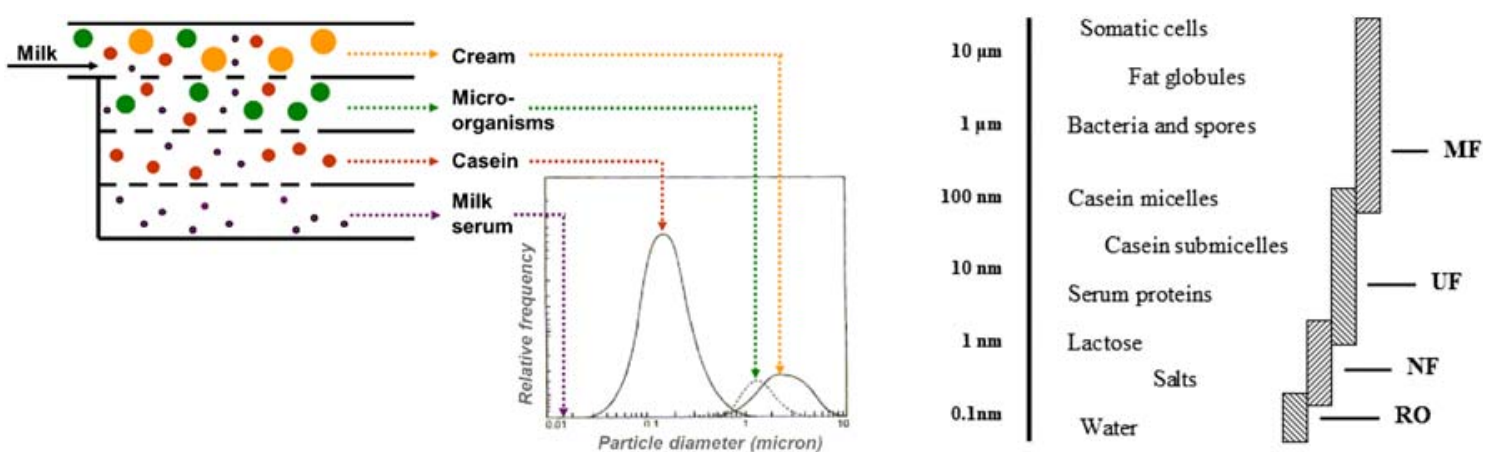

Fig. 2 Illustration of the basic idea of milk fractionation with membranes (left) and comparison of size of dairy components and available membranes (MF microfiltration, UF ultrafiltration, NF nanofiltration, RO reversed osmosis (adapted from [65]; both figures are in [17]))

than $300,000 \mathrm{~m}^{2}$ are installed for food processing, and of that $40 \%$ is used in dairy [51]. Among others, the following applications have been reported [114], here arranged based on pore size of the membrane:

- Reduction of bacteria and spores in skim milk (microfiltration; bactocatch system)

- Separation of fat globules, from whole milk or cream (microfiltration)

- Concentration of casein micelles prior to cheese making (ultrafiltration)

- Production of native casein protein isolates (ultrafiltration)

- Fat removal from cheese whey (ultrafiltration)

- Purification of serum (whey) proteins (ultrafiltration and dialysis)

- Recovery of lactose (nanofiltration)

- Brine purification in cheese processing (nano/ultrafiltration step in the brine circulation)

Lately, also forward osmosis $[21,148]$ and thermo-dialysis $[46,47]$ have been suggested for concentration purposes of dairy stream such as milk and whey, leading to water removal at low energy input. For more information on water treatment by reverse osmosis, which is also very important for food production, the interested reader is referred through to a recent review [5].

Developments in membrane systems have seen tremendous growth in the past decades and have revolved around enhancing mass transfer in the membrane modules. Mass transfer is scaled to the height of the channels or diameter of the fibers. One may ask however whether this is the determining scale. The pores are much smaller as the channels, and the components may even be even much smaller than the pores. Although from a classic membrane perspective (prevention of accumulation on the membrane surface), application of turbulence may seem desired, it also precludes separation based on specific particle behavior driven by processes on a quite different scale, typically the micrometer scale (as described in the next section).

\section{Behavior at Micrometer Scale}

\section{Flow}

In pressure-driven membrane systems, all components present in the feed are brought to the membrane surface due to convective flow, but may also diffuse away from the membrane and thus resolve part of the problem that they cause. Relevant particle migration/diffusion phenomena have been studied as early as 1966 when Segré and Silberberg [117, 118] showed that particles naturally move away from a wall, which in filtration would be a natural way to keep a separation process running longer. For small components $(<0.1 \mu \mathrm{m})$, Brownian diffusion is the ruling random mechanism, while for larger ones (typically $>10 \mu \mathrm{m}$ ), inertial lift will play a role. In the 1980 s, people were investigating these mechanisms for membrane applications (e.g., [2, 9]; Georges [10]) and found that the intermediate category particles that are typically $1-10 \mu \mathrm{m}$ are susceptible to shear-induced diffusion. This process occurs due to particle interactions that effectively move them toward the middle of the channel, and this was exploited in membrane processes (e.g., $[28,62,66])$ and even included in flux models to some extent $[26,27]$. Shear-induced diffusion formed the basis for the critical flux concept [38].

Using particle migration (shear-induced diffusion or inertial lift) as a basis for filtration/fractionation is now seeing a revival $[30,115]$. Better manufacturing processes that allow control over pore size and other membrane properties bring applications closer to reality. In order to make use of these effects, the amount of liquid that is removed through the permeate needs to be tuned to the diffusive flux in order to prevent particles from going to the permeate. It was shown that this is possible making use of shear-induced diffusion [136, $137,138]$ and also inertial lift [30]. In order to be effective, the porous area needs to be preceded by a closed channel in which the particles can migrate away from the wall [126], as also confirmed by simulations presented by [143, 144]. The pores can be much larger than the components that need to be retained $[137,138]$ since the particles have moved away from 
the wall, and a certain amount of liquid can be removed without accumulating particles on the membrane surface (Fig. 3). In the work of Dinther that is mentioned before, the pores are typically $20 \mu \mathrm{m}$, whereas the particles/droplets that are separated are only a few micrometers.

This principle, called ShIFT (Shear Induced Fractionation Technology), is still in its early stages of development, but does show that if unconventional principles are taken as a starting point for separation design, novel fractionation technology may be within reach. ShIFT is expected to be more energy efficient (typically $20-30 \%$ of the energy needed compared to regular microfiltration) since flow does not need to be turbulent [115]. In order for ShIFT to be effective, it is important to have relatively uniform pores to keep the same conditions over the length of the membrane, which may need to be rather short compared to what is used in microfiltration.

We were able to measure ShIFT effects in a practical system as illustrated in Fig. 4, in which transmission of emulsion droplets of $2.7 \mu \mathrm{m}$, and $5.3 \mu \mathrm{m}$ diameter $\left(\mathrm{d}_{32}\right)$ present in a 1:1 volume ratio, is shown as function of the total volume fraction of droplets [136] at a specific flux. The membrane/metal sieve had round pores of $20 \mu \mathrm{m}$, and the module had an entrance length of $30 \mathrm{~cm}$ (= closed channel) that preceded the filtration area $(1 \mathrm{~cm})$. For the tested process conditions, the transmission of large particles was always zero at high concentrations while the transmission of small ones was even higher than one, indicating enrichment of this fraction (left part of the graph). At lower concentrations, the transmission of large particles was higher and of small particles lower. This indicates that shear-induced diffusion is strongly concentration-dependent and was not pronounced enough for segregation to occur given the process conditions that were used [137]. In other work, we could get this separation to work at lower concentrations by adjusting the ratio of transmembrane pressure [115] albeit using another mechanism called fluid skimming, which can be used to send particles of various sizes across pores or to be captured by them. Basically, the size of the particle determines how deep it will "sink" into the pore given a certain flux, and since larger particles need to sink in deeper, they are less likely to be captured.

The actual fluxes were at least as high as measured in regular microfiltration $\left(100 \mathrm{~L} / \mathrm{m}^{2} / \mathrm{h}\right)$. Interestingly enough, the separation does no longer depend on the pore size since the pore size is much larger than the two droplets separated. In this case, the process conditions can be used to tailor the

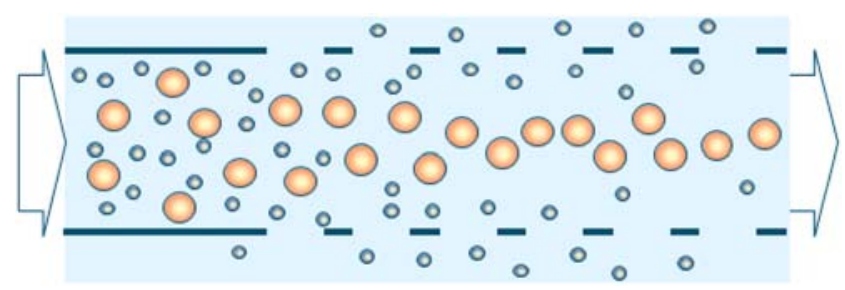

Fig. 3 Schematic representation of the ShIFT principle

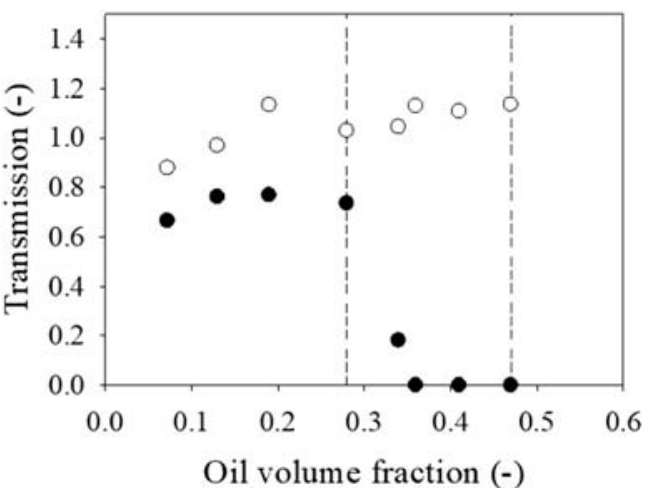

Fig. 4 The transmission of large (black symbols) and small (open symbols) droplets measured as function of the total volume fraction. Image reprinted with permission from Van Dinther, Schroen, et al., [136]; reprinted with permission from Elsevier

average size in the permeate. Besides, no accumulation of particles occurred on the membrane, and the fluxes were constant as function of time $[115,138]$.

Besides the ShIFT principle, inertia-driven processes in ratchets were recently reviewed by Dijkshoorn [30], and also fluid skimming was described [] as effective ways for particle separation. The underlaying mechanisms of these innovative processes are rather different as those that are currently used on large scale. In order to make most out of the available options, we need to think out of the box and develop drastically different processes that take effects occurring at small scale as a starting point (see, e.g., [99] for examples from the food field), as illustrated in the section on small and large scale comparison.

\section{Clogging}

Current developments in the field of microfluidics allow imaging of various processes that are relevant for membranes. The scale at which these devices can be made is typically slightly larger than the dimensions of membrane pores, but the gap is closing fast. For example, particle migration in a narrow channel $[126,138]$ and pore clogging were tested both for hard [59, 139] and soft particles [15] using pores that were typically $20 \mu \mathrm{m}$ wide.

A number of pores containing constrictions with different angles under which they face the permeating liquid were tested (Fig. 5). It could be concluded that this angle plays a major role in the occurrence of clogging [60]; angles perpendicular to the flow being more prone to clogging. Furthermore, these devices were used to elucidate the effect of cross-flow velocity on cake formation (accumulation layer), and in the first experiments, we clearly saw that the cross-flow helps controlling the thickness of the cake layer (Fig. 5, middle panel), which is not so surprising, but did not affect clogging inside the pores. This also implies that preventing the first particle from sticking to the wall needs to be prioritized in order to keep a 
Fig. 5 Use of microfluidic devices with $20 \mu \mathrm{m}$ constrictions (shortest distance) to demonstrate processes occurring in membranes. In the top left panel (a) schematic of the pore constrictions [127]. Top right (b), a deformable particle passing through a pore [15]. Bottom left (c): three images of the cake thickness measured at different cross-flow velocities $(0,0.2$, and $0.4 \mathrm{~mL} / \mathrm{min}$ ). At the right (d) a representation of the effect of cross-flow velocity on cake thickness [139]. All images were published open access with Scientific Reports
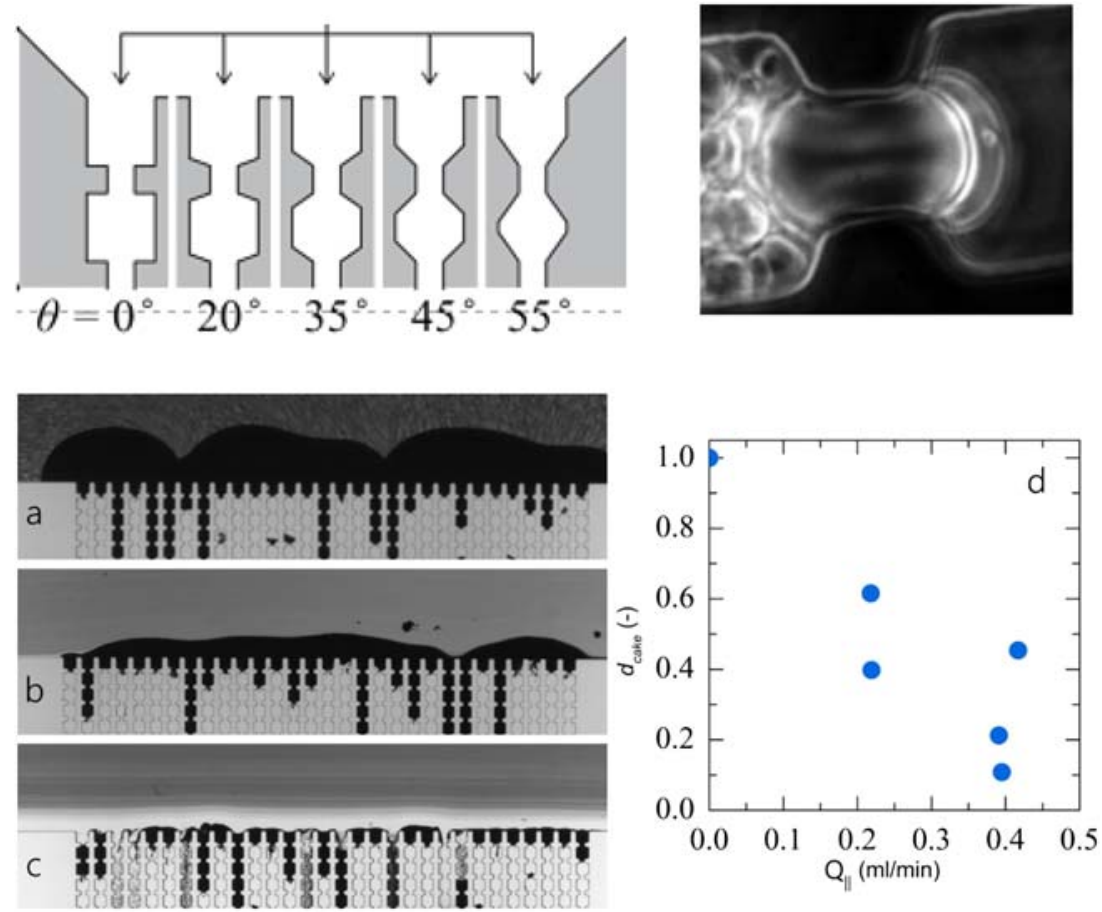

process running for longer, and thus, surface modifications are very relevant to achieve this.

When working with soft particles using exactly the same devices used previously, the situation becomes more complex. In the research of Bouhid de Aguiar [15, 16], soft particles that were close to many food ingredients were tested and unexpected behavior was recorded, as illustrated in the top right panel in Fig. 5. For gel particles that are relatively large (25$40 \mu \mathrm{m}$ ), both deformation and water expulsion play a role in reducing the width of the particle and allowing permeation. For gel particles as they typically occur in foods and that are smaller (typically below $5 \mu \mathrm{m}$ ), water expulsion is expected to be the main mechanism $[15,16]$.

In membrane processes, it is customary to choose a pore size based on the size of a component that is not pressurized and from the above, it is clear that this may not be wise to do since the "size/width" of a component can be rather different under pressure, and deformation can take place. Furthermore, if the particle happens to be a droplet, massive deformation may take place, and even droplet breakup may occur [154]. As mentioned, the devices are not at the exact scale at which they match membranes one on one, but the developments are going fast, and the general learnings that can be taken from these devices are of immediate importance when designing membrane processes.

\section{Emulsification}

During emulsification at large scale, energy is used to break up oil droplets into smaller ones (that may rapidly re-coalesce and thus need to be refined again) and is dissipated as heat. In order to be more energy-efficient, better control over droplet formation would be needed, as is possible in microfluidic devices as described in the sub-section directly below. Besides, additional insights in the interfacial tension acting during homogenization, which determines the ease of droplet formation and the stability of the formed droplets, would be of great value. For this, microfluidic tools have been developed that operate in conditions comparable to those encountered large-scale emulsification, as described in the sub-section below that covers this topic.

\section{Upscaling of Microfluidic Devices}

The amount of energy used for emulsification in microfluidic devices is much lower (typically $5 \%$ or less) than in equipment used at large scale [112]. However, currently, microfluidic systems have low throughput, typically in the microliter/hour range. It is clear that these systems would need to be parallelized extensively to reach the tens of cubic meter/ hour that are required for food production. This is a big step to make, but considerable progress has been made.

In microfluidic emulsification, two approaches are of interest either using shear-based techniques or spontaneous droplet formation as a result of Laplace pressure differences. Within the former category, T- and Y-shaped junctions and flowfocusing devices can be distinguished, and these have for example been arranged around a central channel (Fig. 6a), as demonstrated by $[88,89]$. In order to make uniform droplets, the flow of both the continuous and to-be-dispersed phase 
Fig. 6 Examples of upscaled microfluidic emulsion devices. a (Left) Shear-based units grouped around a central collection pipe (Takasi [88]; reprinted with permission from the Royal Society of Chemistry). b (Top right) Top view of a straight-through emulsification device with droplets forming from slit-shaped terraces (image courtesy of Isao Kobayashi; 2011). c (Bottom right) Multiple EDGE devices on one chip ([131]; reprinted with permission from the Royal Society of Chemistry)

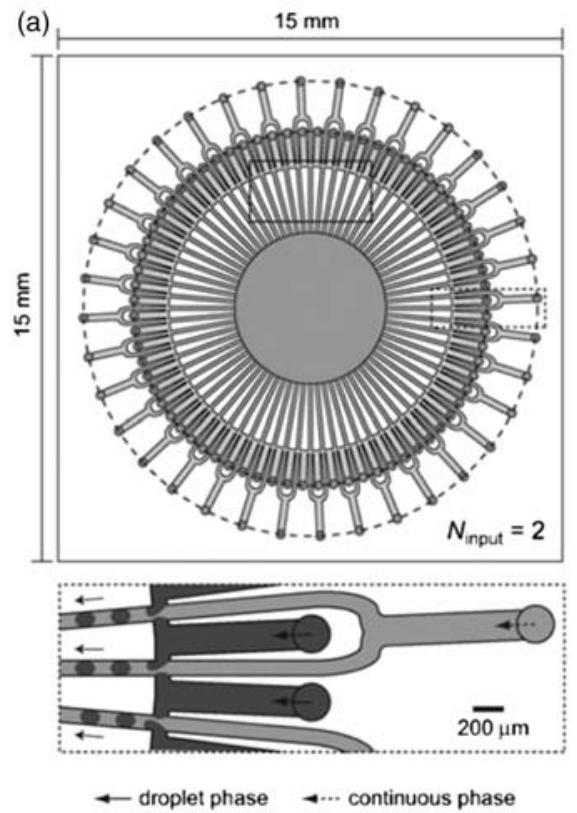

(b)

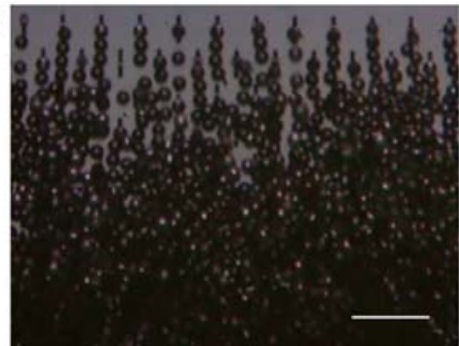

(c)

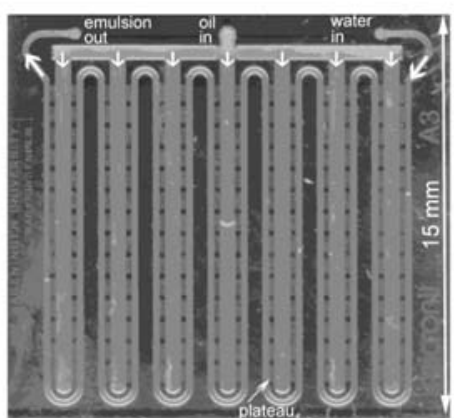

needs to be controlled very carefully, which also limits the number of droplet formation units that can be parallelized since all units need to be individually connected to the feed stream, leading to an excess of tubing.

The work done on microsieve emulsification may be considered as an upscaled shear-based microfluidic technique, since the microsieves have very uniform pores. Various aspects, such as pore activation and interaction, that lead to a reduction in throughput and influence the uniformity of the droplets that are formed have been discussed [42] and also compared to membrane emulsification [43]. Although strictly speaking, membranes are not upscaled microfluidic devices, they have been successfully used in emulsification at low energy input. In this case, the pores are less uniform than in microfluidic systems, but the emulsion droplets that are formed are rather uniform in size. The membrane surface area that would need to be used is still large; thus, application is limited to high added-value products. A good overview of all emulsification methods can be found in the review of [140]. Membrane emulsification in relation to food is reviewed by [20].

Within the spontaneous droplet formation category, microchannels that are organized in planar fashion [] and straight-through systems that are highly parallelized microchannels (e.g. [53, 54]) were developed at the National Food Research Institute in Japan (Fig. 6b). These devices may have lower droplet formation frequency than their shear-based counterparts, but droplet size is easier to steer, since only the to-be-dispersed phase needs to be controlled. In our own lab, we developed an approach that allows for multiple droplet formation points in one microfluidic device. In this so-called
EDGE (Edge-based Droplet GEneration) device [131], very monodisperse droplets can be made, and to some extent, the device has also been scaled up (Fig. 6c), and used in combination with food-grade materials $[131,133]$. More information can be found in the previously mentioned review of [140]. Besides, these devices are specifically discussed for food applications in the review by [67].

Currently, these devices are only considered for high added-value products, although developments go fast. It is envisioned that considerable cost reduction in construction will take place thanks to fast prototyping in polydimethylsiloxane (PDMS) [33], and development of paper-based microfluidics [63, 68, 69], and through 3D printing [32].

\section{Microfluidic Tools for Emulsification}

\section{Dynamic Interfacial Tension Measurement}

For large-scale emulsification, both experimentation and modeling are very challenging. Given the turbulent conditions encountered in the homogenizers, visualization needs to take place at high resolution and short time scales. In addition, there are limitations in simulations for which the NavierStokes equations need to be solved at a local level, using mathematical grids of nanometer scale [100, 123]. Any tool that would be able to facilitate characterization of processes relevant to emulsification would thus be a great asset. For the measurement of the dynamic interfacial tension (i.e., at the moment of emulsion droplet formation), various systems have been suggested (Fig. 7) that approach relevant time scales, as reviewed by Baret [7] and Bremont and Bibette [18]. 

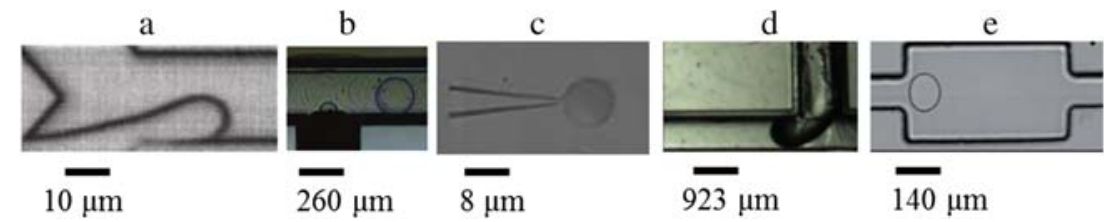

Fig. 7 Microscopic images during or after interfacial tension measurement based on droplet size (a) ([124]; reprinted with permission from the American Chemical Society), (b) ([]; reprinted with permission from the American Chemical Society), and (c) ([152];

Microfluidic methods for interfacial tension measurements have been based on droplet size [124, 147, 152], pressure drop [147], droplet deformability [19], $\mathrm{pH}$ change related to adsorption kinetics [98], jetting/dripping transition [76], and pressure drop in a separate sensor channel [104]. Steegmans and co-workers [124] used a cross-flow Y-junction (panel a), Wang et al. [] a cross-flow T-junction (panel b), and Xu et al. [152] a coaxial device (panel c). In these devices, droplet size depends on the balance between the shear exerted by the continuous phase and the interfacial tension that keeps the droplet attached, thus on the capillary number. All these authors used the droplet size (and capillary number) to determine the interfacial tension at the time of droplet formation. Wang et al. [147] (panel d) use a relation between pressure drop and radius of the growing droplet (through which they calculate the Laplace pressure of the droplet). Brosseau et al. [19] directed droplets through 121 subsequent expansion chambers where droplet deformation was recorded (panel e), and the evolution of interfacial tension was related to droplet velocity, interfacial tension, and droplet radius.

An overview of droplet sizes and time scales in these measurements is given in Table 1. With the method of Steegmans et al. [124], the smallest droplets and time scales can be assessed, which are both relevant for large-scale processes that operate at sub-millisecond range. The effects of various processes and ingredient conditions have been investigated, which is described in more detail in the "Outlook" section.

\section{Y-Junctions}

In order to explain how much microfluidic methods for dynamic interfacial tension measurement differ from conventional techniques such as droplet volume tensiometry, we reprinted with permission from the American Chemical Society); pressure drop (d) ([147]; reprinted with permission from Springer); and droplet deformation (e) ([19]; open access)

dedicate a small section to them. In essence, the Y-junction in which two liquid flows meet under an angle of approximately $60^{\circ}$ (Fig. 8) is rather similar to the T-junction in which liquid flows meet under a $90^{\circ}$ angle [41] in regard to droplet formation mechanism (see also Fig. 8 for images during experimentation). The to-be-dispersed phase is pushed into the continuous phase that distorts it and ultimately breaks off droplets. In case of the Y-junction, droplet growth during the second stage of droplet formation in which the droplet grows further while feeding from the neck (typically going from images 4 to 5 below) has less effect on the droplet volume than reported for T-junctions, which makes the Y-junction easier to interpret.

The droplet size could be predicted with the following equation:

$V=b \sqrt{\frac{1}{C a}}+\frac{c}{v_{c}} \varphi_{d}$

We found that the droplet volume $(V)$ scaled with the inverse square root of the capillary number (defined as $C a=\frac{\eta_{c} v_{c}}{\sigma}$, with $\eta_{c}$ the continuous phase viscosity (Pa s), $v_{c}$ the continuous phase velocity at the junction $(\mathrm{m} / \mathrm{s})$, and $\sigma$ the interfacial tension $(\mathrm{N} / \mathrm{m})$ ), the reciprocal value of the velocity of the continuous phase, $v_{c}(\mathrm{~m} / \mathrm{s})$, and the dispersed phase flow rate, $\Phi_{d}\left(\mathrm{~m}^{3} / \mathrm{s}\right)$. Further, $b$ and $c$ are proportionality constants that can be calculated with great accuracy using (calibration) systems that do not contain any surfactants.

As a next step, droplet sizes were determined in systems that did contain surfactants, and the scaling relation was used to calculate the interfacial tension. In Fig. 9, interfacial tension data with SDS concentrations ranging from 0.01 to $0.5 \%$ are shown. The symbols indicate the values obtained with the microfluidic setup, whereas the lines show values obtained
Table 1 Overview of microfluidic tensiometric methods and characteristic values

\begin{tabular}{llll}
\hline Reference & Method & Droplet diameter $(\mu \mathrm{m})$ & ${\text { Time scale }(\mathrm{ms})^{\mathrm{a}}}^{\mathrm{a}}$ \\
\hline Steegmans et al. [124] & Size & $8-13$ & $0.5-10$ \\
Wang et al. [] & Size & $160-270$ & $20-70$ \\
Xu et al. [152] & Size & $10-180$ & $1-130$ \\
Wang et al. [147] & Pressure drop & $400-800$ & $10-8000$ \\
Brosseau et al. [19] & Deformability & $90-120$ & $10-2000$ \\
\hline
\end{tabular}

${ }^{\mathrm{a}}$ Time between start and end of droplet formation; table reprinted with permission from (Kelly [81]) 
Continuous phase

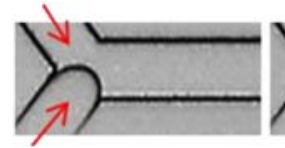

Dispersed phase

1
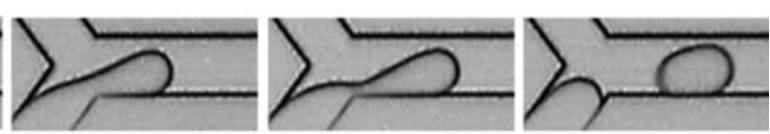

Fig. 8 Oil droplet formation in a Y-junction microfluidic device (reprinted with permission from Elsevier, [78]). On panels (1-3) (starting from the left), the first stage of droplet formation, referred to as the growth step, is shown. Panel (4) shows the second stage of droplet formation, with a neck still connecting and feeding the forming droplet. Panel (5) shows the droplet just after detachment with a droplet volume tensiometer using the same concentrations. As references, horizontal lines are drawn that correspond to the interfacial tension of the bare hexadecane-water interface (top) and to the interfacial tension at full surface coverage by SDS (bottom).

In Fig. 9, the trends in interfacial tension are as expected; at short droplet formation times, the interfacial tension at droplet breakup is high, and the longer the droplet formation time, the lower the interfacial tension becomes. Besides, there is also a clear effect of the surfactant concentration, with high concentrations leading to much faster reduction in interfacial tension. Quite remarkably, this method allows evaluation of dynamic interfacial tension at droplet formation rates between 1000 and 10,000 droplets per second, allowing for analysis at submillisecond scale, which is in the same range as the operation of large-scale emulsification devices. This is not easily approachable by a standard analytical device as illustrated from the results obtained with the droplet volume tensiometer (solid lines on the right part of the graph in Fig. 9). SDS adsorption in the droplet volume tensiometer is fully diffusion-driven, and although it is often thought that molecular transport in microfluidic devices is governed by diffusion given the low Reynolds numbers that are reported that are typically $<10$, the results in Fig. 9 indicate that mass transfer is extremely fast. We expect that this is due to the very fast retraction of the oil column after droplet formation, which enhances mass transfer.

In principle, the microfluidic Y-junction can be used for rapid screening of emulsion components (initial results are available for proteins; [45]), and the obtained data can probably be used to predict effects occurring in the more classic emulsification devices that operate at similar time scales. It is good to mention that the mass transfer conditions may still be different, and that is therefore a point of attention (see "Outlook" section).

\section{Emulsion Stability}

Besides formation of droplets, the physical stability of droplets during production and storage time is important, i.e., their susceptibility to coalescence and flocculation. For this, microfluidic devices can be(come) of great added benefit, as suggested by $[57,58]$. They developed coalescence chambers in which droplets are generated at microfluidic T-junctions and then led into a coalescence chamber (see Fig. 10 left for protein-stabilized droplets). While moving through the chamber, the droplets come into contact with each other, and
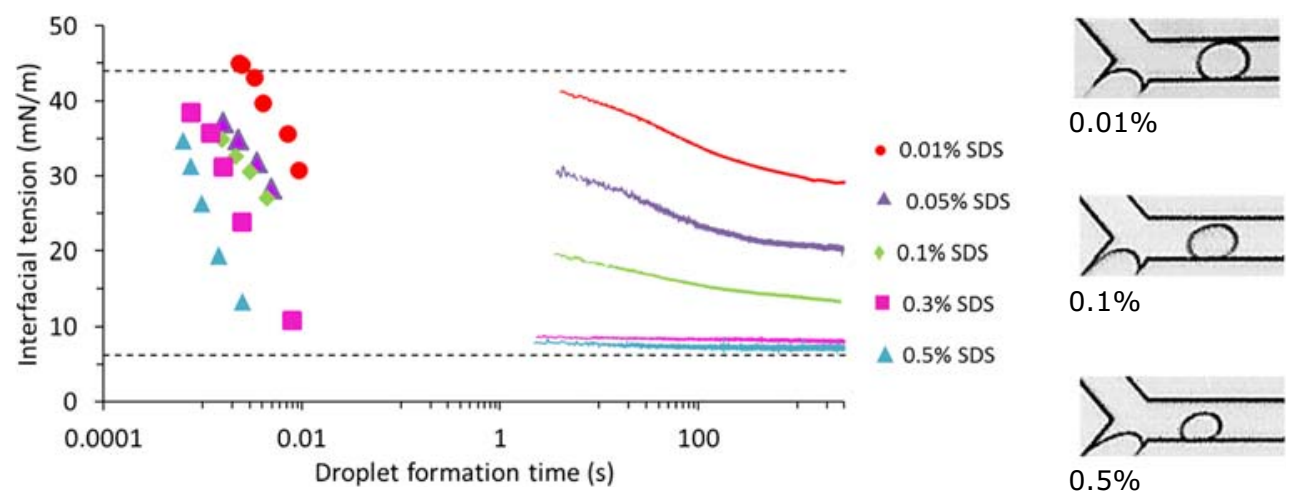

Fig. 9 Interfacial tension at the hexadecane-water interface with various sodium dodecyl sulfate (SDS) concentrations in the aqueous phase, as measured with a microfluidic Y-junction (symbols) and with a droplet volume tensiometer (solid lines). The dotted lines represent the equilibrium interfacial tensions between hexadecane and water (top) and between hexadecane and a 1\% wt. SDS solution (bottom). On the right images of droplets made for the indicated SDS concentrations at a droplet formation time of $1.5 \mathrm{~ms}$. Adapted from [82] with permission from Elsevier 

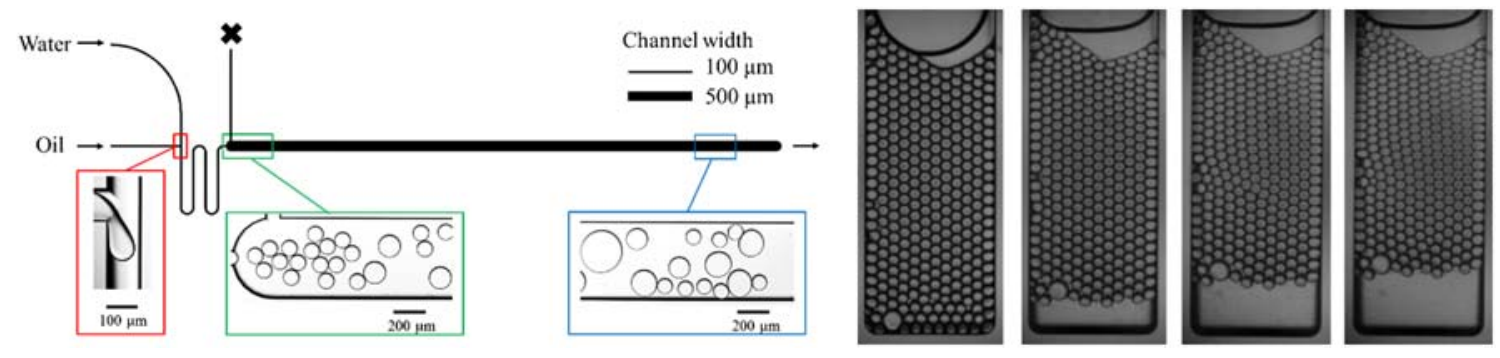

Fig. 10 a (Left) Layout of the microfluidic chip with a T-junction (red rectangle) as droplet formation unit, a meandering adsorption channel length of $14.8 \mathrm{~mm}$, and a coalescence chamber. The green and blue rectangles indicate the regions from which images were recorded, with examples. Reprinted with permission from Elsevier [77]. b (Right) Images during microcentrifugation of an emulsion that is captured in a

possibly coalescence occurs, of which the events are registered through high-speed imaging. In this way, process conditions and emulsion properties (dispersed phase fraction, emulsifier concentration) can be linked to the stability of emulsions $[57,58,77]$; see also next section for further use of this device.

The shelf life of emulsions in relation to their physical stability is often tentatively predicted by application of enhanced gravity conditions, which accelerate the gravitational separation that may occur upon storage. This is also possible using microchips. A microcontainer filled with a monodisperse emulsion (preliminary formed in a microfluidic cross-flow junction) is put in a purpose-built centrifuge [56]. This leads to the continuous phase being expelled at the bottom, and droplets becoming hexagonal in shape (see Fig. 10). For this specific emulsion, this hardly led coalesce at the concentrations and conditions used in Fig. 10 (right panel).

This shows that analysis can take place at individual droplet level in combination with time scales that cannot be assessed with conventional techniques (e.g., $>1000 \mathrm{~g}$ is applied). This leads to quantitative dynamic information about the structural changes occurring. These insights are relevant chamber in which a monolayer of droplets is present. During compression, going from left (first image, $t=0.03 \mathrm{~s}$ ) to right (last image, $t=$ $38.5 \mathrm{~s}$ ), the continuous phase is expelled at the bottom of the chamber, while the droplets are compressed but do not coalesce (from [56]). The size of the smallest droplets is around $60 \mu \mathrm{m}$. This image is reproduced with permission from the Royal Society of Chemistry for comparison of new ingredients, process conditions (such as temperature, [37]), and further development toward highthroughput screening.

\section{Combination of Adsorption Time and Coalescence Stability}

It is even possible to decouple time scales, as they would occur during protein adsorption and droplet coalescence. In Fig. 10a, the layout of a specific coalescence microfluidic device is presented, but the length of the meandering channel (after the red rectangle) can be varied, as well as the concentration of the tested protein. In Fig. 11, the droplet coalescence frequency is plotted as function of the adsorption time (i.e., residence time of the droplets in the meandering channel) of whey protein isolate, a commonly encountered food emulsifier [77]. It is clear that at low concentrations and short residence times, much more coalescence takes place, as is also illustrated in the photos on the right. It was remarkable that the droplets were extremely stable already at low protein concentration $(0.01$ and $0.02 \%)$ when given sufficient time for adsorption to take place. The typical concentrations are quite lower than those applied in usual food emulsions, and this
Fig. 11 Mean coalescence frequency as a function of the adsorption time, and microscope images from the outlet of the collision channel with $0.001(\nabla)$, $0.002(\Xi), 0.01(\mathbf{\Lambda})$, and $0.02(\bullet)$ $\mathrm{wt} \%$ whey protein isolate. The error bars indicate the standard deviation of the three recordings taken per measurement.

Reprinted with permission form Elsevier [77]

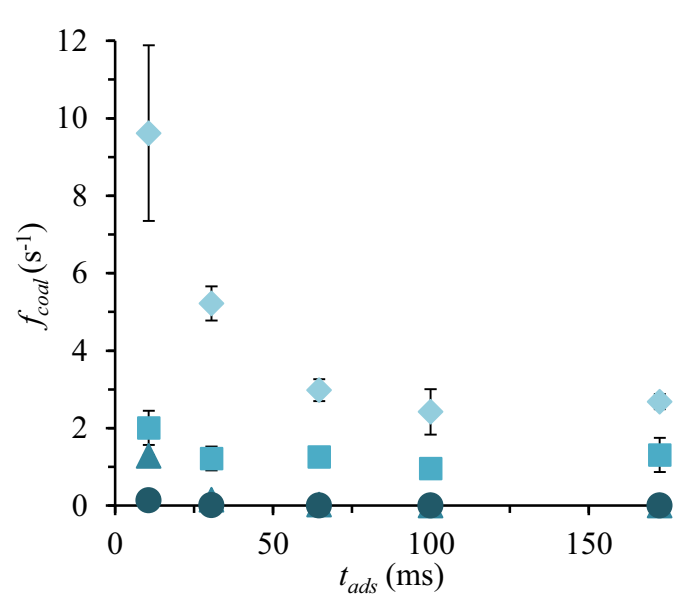

$t_{\text {ads }}=173 \mathrm{~ms}$

Whey protein isolate (wt. \%)

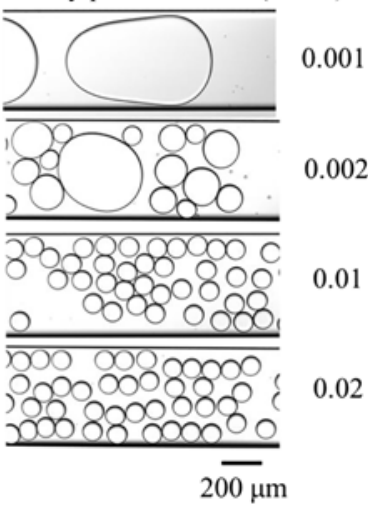


could have to do with the fact that in classic emulsification devices, the droplets do not get sufficient time for protein adsorption to take place and re-coalescence could then be the determining factor [77]. We need to keep in mind that the observation time in the microfluidic devices is very short; the results obtained should be interpreted in terms of trends that are expected to occur at longer time scales, but cannot be translated one on one.

\section{Comparison of "Micro" and Large-Scale Operation}

In this section, we will show through illustrative examples how data gathered at small scale are useful in the development of innovative processes and for processes as they are currently carried out at large scale. We focus on energy efficiency and discuss how the insights may lead to developing more sustainable food products and ingredients. We first do this for filtration, and emulsification, and follow up with the various tools discussed earlier. In the outlook section, we discuss the next steps for the use of microfluidics in rational food product design.

\section{Filtration Processes}

In this part, we compare data that were obtained for yeast removal from beer. Details on the calculations for microfiltration are given in $[115,134]$; we have based these calculations on very general conditions used for this process: a pore size of $0.45 \mu \mathrm{m}$, cross-flow velocity of $2 \mathrm{~m} / \mathrm{s}$, and a flux of $100 \mathrm{~L} /\left(\mathrm{m}^{2} \mathrm{~h}\right.$ ) (in line with [90], who investigated this process in great detail for beer filtration). The yeast cells are 2 to $10 \mu \mathrm{m}[14,40]$, and their concentration is $0.03-0.7 \%$ before beer clarification. According to the standards of the European Brewing Convention, the critical size of particles entering the permeate is $0.8 \mu \mathrm{m}$ [8], which is taken as the cutoff value for all processes.

Given the size of yeast, shear-induced diffusion (the earlier described ShIFT process) and skimming/inertial lift are both relevant. For the calculation below, we took insights obtained from the work of van Dinther (all entries in the literature list). The sieve porosity is $15 \%$, the flux is $50 \mathrm{~L} /\left(\mathrm{m}^{2} \mathrm{~h}\right)$, and the cross-flow velocity is $0.19 \mathrm{~m} / \mathrm{s}$, which is $\sim 1 / 10$ th of the value for microfiltration. The membrane length was $4.6 \mathrm{~cm}$ (porous area) which was preceded by a closed channel of $0.3 \mathrm{~m}$, and sieve resistance was $1 \times 10^{12} \mathrm{~m}^{-1}$, which is reasonable given the large pores.

The energy needed for the novel systems is considerably lower than reported for the standard technology (Kiezelguhr) and for regular microfiltration (Table 2). Since the flux of the innovative process is half that of the microfiltration process, the (membrane) area that needs to be installed is twice as large; but since the cross-flow velocity is much lower, the energy costs related to that are much lower and the main cause for the lower energy consumption, which may legitimize the installation of more membrane area and related investment [115].

For these innovative processes to work properly on large scale (up until now, only lab-scale has been used), the design of the sieves/membranes is of essence. Although it is often claimed that some membranes have much more uniform pore size as their competitors, for the current innovations, the control over pore size would need to be much greater as normally possible for porous membranes prepared by phase inversion as recently reviewed from a materials perspective by [149].

In principle, relatively large but uniform pores would be needed, and these are to some extent also available. For example, using clean room technology, so-called microsieves were made and commercialized by Aquamarijn microfiltration (https://www.aquamarijn.nl/) and also translated into polymeric versions [141, 142]. Furthermore, metal sieves with well-defined pores (https://www. vecoprecision.com/) made through electrochemical processes are even available at square meter scale. Also in membranes, small and uniform pores have been produced, and considerable effort is put into this, especially at The Advanced Membranes and Porous Materials Centre at KAUST (Saudi Arabia, profs. Nunes and Peinemann; e.g., [92]) although making large surface areas with constant properties is still a great challenge. Alternatively, also 3D printing could be a way to go given its unprecedented control over membrane structure (as recently reviewed by
Table 2 Comparison of processes for yeast separation based on energy consumption per hectoliter $([115,134]$; reprinted with permission of Elsevier)

\begin{tabular}{lll}
\hline Process & $\begin{array}{l}\text { Energy consumption } \\
(\mathrm{kWh} / \mathrm{hL})\end{array}$ & Principle \\
\hline $\begin{array}{l}\text { Kieselguhr filtration (electric power } \\
+ \text { steam) }\end{array}$ & 0.13 & Dead-end filtration with filter aid [90] \\
$\begin{array}{l}\text { Conventional microfiltration } \\
\begin{array}{l}\text { Microfiltration based on fluid } \\
\text { skimming }\end{array}\end{array}$ & 0.11 & $\begin{array}{c}\text { Cross-flow microfiltration in constant flux } \\
\text { regime [90] }\end{array}$ \\
$\begin{array}{l}\text { Concentrated yeast cell } \\
\text { microfiltration }\end{array}$ & $7.7 \times 10^{-3}$ & Fluid skimming/inertial lift [] \\
\hline
\end{tabular}


[64]). At this very moment, the production of larger surface areas is still far from trivial, but developments are going extremely fast in this field.

\section{Filtration Tools}

The presented filtration tools are very useful to elucidate the underlying processes in filtration and have rendered many insights that are otherwise impossible to unveil based on the traditional, macroscopic, flux/retention approach that is often used. We could design pores in detail and found for example that if the pores containing constrictions with walls perpendicular to the permeate flow, their propensity for clogging was much greater than pores with more gradual constrictions. Furthermore, we could show that the interaction between the wall and the particle was a determining factor for the rate of clogging [60], and that deformability of gel particles led to unprecedented permeation behavior. Particles that were a number of times the size of a pore still squeezed through by expelling water in combination with unexpected deformations.

Together with the developments mentioned earlier for membranes with uniform pores, the level of detail that can be investigated with these microfluidic tools will allow us to develop membranes on various levels. This ranges from the actual pore geometry that may be chosen such that minimal clogging will occur to specific surface modifications that influence the interaction between wall and components in such a way that no particle will stick, and that thus the onset for clogging is removed. Obviously, this is still rather futuristic, but through these tools, the choice of an appropriate membrane could be decided on rather different grounds as currently done (mainly the pore size).

\section{Emulsification Processes}

It can be expected that when using microfluidic devices, recoalescence will be lower than for conventional homogenization because they allow more time for interface stabilization, and in this sense, upscaling of microfluidic devices could be an interesting option as also mentioned before. Mostly, upscaled devices are used to produce relatively large droplets (diameter $=91 \mu \mathrm{m}$; [89]). For spontaneous microfluidic methods, large droplets have been reported for STEP emulsification [93], whereas with EDGE and straight-through devices, smaller droplets can also be formed (diameter $=4$ $10 \mu \mathrm{m})$ and the size is less sensitive to changes in process conditions ([3, 55]; Sami [107]). The typical amounts of product that can be achieved make these devices suitable for low volume, high added-value applications; for large-scale application, the efficacy is not high enough yet, although considerable progress has been made. For example, we have made adjustments to the EDGE (Edge-based Droplet GEneration) device, which is unique in its ability to produce multiple droplets from one droplet formation unit. In doing so, we have increased its throughput 100 -fold and also found that we could operate the device in two stable droplet formation regimes [106]. We even have taken the first steps toward upscaling $[107,112]$, in which we are at the border of manufacturing possibilities. Also here, it can be expected, as was the case for membranes, that more control over the hierarchy of the droplet formation units will be within reach soon. We like to mention the fast given developments in 3D printing [32], but also in making the devices cheaper (paper microfluidics even exist and have been reviewed; [4, 63]). This will also be instrumental to other multiphase products such as foams, as recently reviewed [29].

When highest monodispersity is not of the essence, premix membrane emulsification can be an option. From Table 3, it is clear that this device operates at fast droplet formation times; basically, the starting point is a coarse emulsion that is refined by passage through a microstructured device/membrane as reviewed by [84]. Very high fluxes have been reported especially for metal sieves similar to the ones previously mentioned in the membrane section (typically hundreds of $\mathrm{m}^{3} / \mathrm{h} /$ $\mathrm{m}^{2}$ ) [, 85]. When using traditional membranes for this, they can get blocked rather easily, and they are difficult to clean. In that respect, the system suggested by [, 130], which makes use of a bed of glass beads supported by a metal sieve (https:// www.vecoprecision.com/), could be of interest. To illustrate this further, for droplets of $1 \mu \mathrm{m}$ and below, as is often the target in food applications, the smallest dimension of a regular microstructure would need to be $\sim 200 \mathrm{~nm}$. Although microfluidic devices of these dimensions can be made, making them reproducibly and at high numbers is a great challenge for microfluidics manufacturers. For the glass bead system, the typical interstitial void size can be 5 times the size of the droplet diameter, so in this example could be $5 \mu \mathrm{m}$, and that can be achieved much more easily.

\section{Emulsification Tools}

Emulsification is most efficient when there is minimal rapid re-coalescence of the droplets and for that, emulsifiers should stabilize the interface before droplet collision takes place. Typical droplet formation time scales are given in Table 3 for various emulsification devices, including the microfluidic devices presented earlier (an extensive overview of characteristic times during emulsification can be found in Marilyn [97]). In the coalescence channel, the time for adsorption to take place (droplet formation time and adsorption time in the meandering channel) is relatively long and can be used to compare with emulsion formation in colloid mills, direct membrane emulsification, and spontaneous microfluidic emulsification. Y-junctions can be used to study faster processes such as the high-pressure homogenizer, premix 
Table 3 Adsorption time range of various emulsification devices and of the used microfluidic devices ([81]; reprinted with permission of the author)

\begin{tabular}{ll}
\hline Emulsification device & Droplet formation time range (s) \\
\hline High-pressure homogenizer & $10^{-4}-10^{-2}[116]$ \\
Colloid mill & $10^{-1}-10^{0}[116]$ \\
Direct membrane emulsification & $10^{-2}[129]$ \\
Pre-mix membrane emulsification & $10^{-6}-10^{-1}([] ;[87])$ \\
Spontaneous microfluidic emulsification & $10^{-2}-10^{-1}[55]$ \\
Shear-based microfluidic emulsification & $10^{-4}[88]$ \\
Y-junction & $10^{-4}-10^{-2}([79] ;[80])$ \\
Coalescence channel & $10^{-2}-10^{-1}[77]$ \\
\hline
\end{tabular}

membrane emulsification, and shear-based microfluidic emulsification.

In principle, it is possible to use the microfluidic methods, such as the Y-junction and coalescence channel, to conduct formulation screening in high-throughput mode, allowing detailed analysis of the kinetic behavior of the surface active components, therewith having the potential to speed up product formulation design. Currently, most papers have been dedicated to simple surfactants, and some work was done on proteins in emulsions $[44,45,50]$. It is expected that also other emulsifiers such as polymers and particles can be used [110], that is, as long as the wettability of the microfluidic device is not affected $[119$,$] . If that happens, one of the phases may$ start sticking to the device wall, therewith disturbing droplet formation and further analysis. Still, the devices were found to be rather resilient, as demonstrated in a paper of [108] also for protein-stabilized emulsions and foams produced with EDGE devices [132].

It is good to point out that the devices are very sensitive, and remarkable differences in emulsion stability were found when using, for example, oxidized dairy proteins that have lower interface stabilization efficiency than their nonoxidized counterparts $[11-13,77]$. For oxidized plant proteins, we found for example that a moderate level of oxidation contributed to short-term emulsion stability (ongoing research within our group: [50]). Protein oxidation leads to, among others, hydrolysis and aggregation, the first one leading to relatively fast reduction of interfacial tension, but also to much thinner interfacial layers that are less protective against coalescence $[77,111]$.

In food, emulsifiers are often used as a mixture that may contain low molecular weight surfactants, proteins, polymers, etc., which will affect interfacial behavior [95] and possibly coalescence stability, which can be elucidated with the microfluidic tools described earlier. The emulsifier mixture can be used as the continuous phase or added to the dispersed phase [79] or a second emulsifier can be added after droplet formation in the coalescence chamber via the extra channel that is designed for that purpose (see Fig. 10, indicated by the cross). Also polysaccharide-protein complexes can be used for this purpose. In literature, it has been described that they can either be added to emulsions as such or formed in situ by addition of, for example, a polysaccharide to a proteinstabilized emulsion (e.g., [35, 102, 105]). The use of physically [75] and chemically or enzymatically modified proteins (e.g., hydrolyzed; [1]), cross-linked [36], succinylated, acetylated, or deaminated proteins [61] has been described, and in principle, their emulsification efficiency can now be accessed using the microfluidic methods presented here. Skhiri and coworkers [120] have also investigated surfactant displacement using microfluidics although at longer time scales than typically relevant for emulsion production. In our view, it is only a matter of time for these powerful microfluidic devices to become part of formulation research since they allow quantitative comparison at time scales that otherwise could not be assessed. This draws considerable attention to this innovative field, as it could be instrumental in, for example, the protein transition for which a switch needs to be made from animalbased proteins to their plant-based counterparts (e.g., [49]).

\section{Outlook}

In the previous section, existing techniques were discussed; in the current section, we go one step further and give a flavor of developments that take place and that could put food (including prevention of food waste), and its effect on digestion and health, onto a completely new level. We first discuss the use of sensors to warrant food safety based on the quality of the food $[109,150]$. Further, we show digestion in microfluidic chips [70] and bioavailability of components [71] and take it even one step further to organs on chips that were recently reviewed by [122] and how they may be used to generate the information needed for intrinsic rational design of healthy food products.

\section{Sensors Related to Food Quality}

The use of sensors has developed very rapidly in the food field $[34,74,150]$, to signal a change in gas atmosphere (including 
the "bioelectric nose"), the presence of specific microorganisms, and the temperature trajectory that the product went through in relation to freshness as reviewed recently by [94]. Mostly the gas composition is targeted as reviewed by [73] and specifically investigated for fish by [48]. Ideally, this leads to a situation in which the consumer "knows" the freshness of a product (for examples, see Fig. 12 in which a traffic light indicator is used), and no longer needs to rely on the expiration date now commonly used. This latter indicator leads to premature disposal of foods that can safely be consumed and thus food waste on large scale [91]. Just to illustrate this, in the Netherlands, approximately one third of the food is wasted at supermarket level, and also one third of the food arriving at people's homes is discarded as waste (https://www.wur.nl/en/ Dossiers/file/Dossier-Food-waste.htm).

In primary analysis of, for example, starting materials, small chips with nanoparticles and nanowires can be used to, for example, identify specific microorganisms through interaction with antibodies and through gas composition. A big advantage of microfluidic (maybe even nanofluidic) sensors in general is that it is possible to perform detection in extremely small amounts of sample. Whether such sample would also contain the analyte of interest is still a question that needs to be answered on a case to case basis. Some concentrations are simply very low and, in spite of the very high accuracy/ resolution that can be achieved, still require considerable concentration of the samples (e.g., for pathogenic microorganisms, allergens). It is good to know that sensors are already extensively used in other fields such as the chemical industry to allow much closer process control by, for example, in-line monitoring and in pharma to warrant the quality of medication. These developments are expected to make the technology cheaper and bring it within reach for application on many different levels, ranging from basic analysis to food process control and food product quality monitoring.

A good overview of sensors developed to assess food safety and quality can be found in [150]. Specific information can

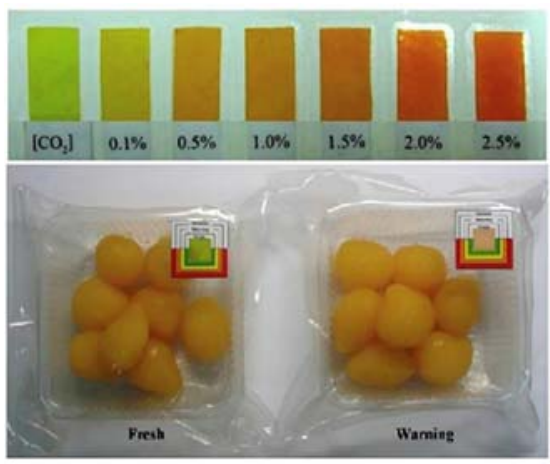

Fig. 12 Examples of sensors used for food products. (Left) Images from [91] in which the spoilage process was monitored in packaged "golden drop" plums; in the top part, changes in color of indicator label are shown in response to $\mathrm{CO}_{2}$. Reprinted with permission from Elsevier. (Right) be found in the following references for recognition of microorganisms [52, 151, 153, ], allergens, [146, 148], and other components $[6,31]$. Furthermore, work has been done on flavors using an electric nose in combination with microfluidics [23]. Even a number of applications have been made compatible with smart phones [96] to allow remote sensing/analysis. All these options make it clear that improvement of quality control, either in the factory, during transport, or at the consumers' home can be taken to the next level.

\section{Digestion on Chip}

Currently, the development of sensors for specific analytes is taking a high flight. However, much less effort is put into using microfludics in digestion research. Obviously, the complexity thereoff may be expected to be quite higher as for analysis of components, but we think that there are considerable similarities. Foods as such are complex mixtures, and that already puts considerable demands on sensors that are developed for that purpose. In Fig. 13, two examples are shown of digestive microfludic tools that are used to monitor digestion of fish oil [72] and of protein [22]. In the figure on the left, small structures are used to capture oil droplets that flow through the system. Once all features contain a droplet, digestive liquid is pumped into the system, and digestion can be monitored in time through the size of the droplets.

In the work of Cheng and co-workers [22], a "long" microchannel is used to digest proteins for a specific time that can be very accurately controlled through the pump rate and channel dimensions. The resulting peptides in the efflux can be monitored at high signal to noise ratio using MALDI-TOF MS. This application was developed in the field of proteomics, and we feel that similar approaches are valid for food proteins that would not behave essentially different. Both systems are thus of interest and could be early indicators for bioaccessiblity of food [70].

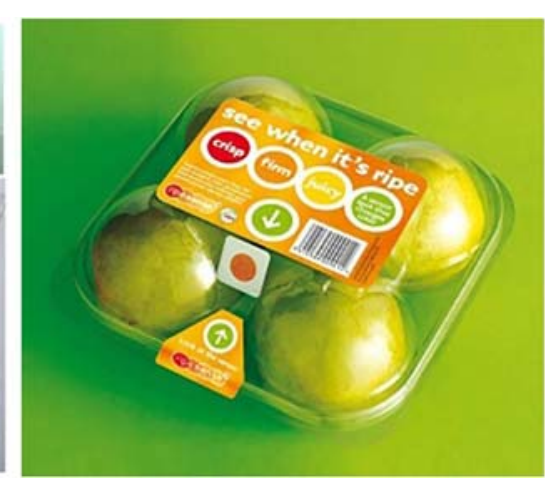

Packaged apples of which the ripeness is indicated through an ethylene sensor (https://www.nanopack.eu/2018/02/09/future-packaging-already/ intelligent-packaging/) 


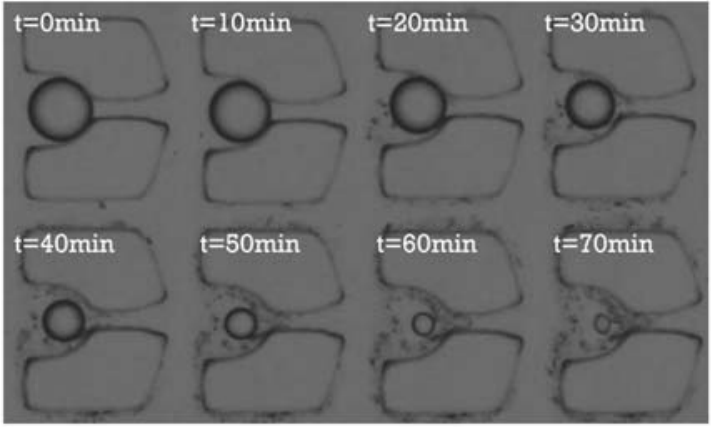

Fig. 13 Examples of microfluidic systems used to investigate digestion of oil (left; [71]) and protein (right; [22]). The left chip contains capturing features for oil droplets that are digested as function of time, leading to reduction in droplet size. In the right figure, protein solutions are sent through a long channel in the presence of digestive enzymes that are

We expect that the microfluidic emulsification devices mentioned before, such as the Y-junction, can be used to investigate digestion. Although indirectly, we have found that elaborate interfacial design was not able to prevent digestion of food emulsions, although literature seems to suggest else [24]. In a droplet volume tensiometer and a reflectometer [25], the interfacial structure disintegrated under digestive conditions. Using for example the coalescence cell, it will be possible to distinguish between oil hydrolysis (decrease in droplet size) and destabilization of the interface leading to coalescence, simply by monitoring the changes in the size of the droplets through extensive image analysis, which would also allow for statistically sound conclusions.

\section{Organs on a Chip}

Organs-on-chips have been developed primarily to investigate processes that take place at cell/organ level as replacement for test animals and are known for their precise control over the microenvironment unlike "classic" cell culture. In essence, these devices can be dedicated to one organ and even made specific on individual level starting from stem cells [128]. Often the term personalized medicine is used in conjunction with organs on chip, which also puts this application of microfluidic systems in the pharmacological field and not really in the food field.

Still it is interesting to philosophize what the use of such combination of devices as shown in Fig. 14 could mean for food, especially when a system would be personalized [122]. Staying close to pharma, this could be a way to, for example, test the effect of various components very efficiently, e.g., for allergies that ingredients may induce, and effects related to bacteria on person level. Besides this, the use of organs on a chip can be seen as the next step after digestion on a chip and will allow testing the bio-efficiency of the components that are present in food at cell level. This would give essential information on how the structure in food may contribute or interfere with release of components as has been investigated to some extent in our lab for

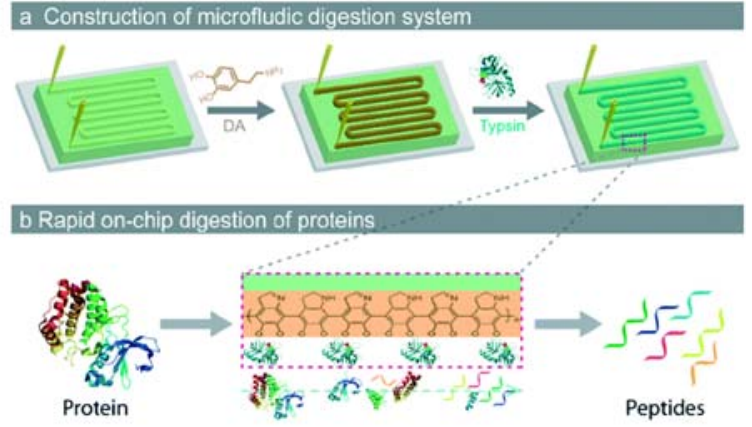

dosed in, and digestion is monitored through the peptides formed using matrix-assisted laser desorption/ionization time-of-flight mass spectrometry (MALDI-TOF MS). Both images are reprinted with permission from the Royal Society of Chemisty

encapsulates with a controlled release as function of $\mathrm{pH}[101$, 103]. What would also be very relevant is to investigate the processes occurring in the colon as published very recently for a system that also includes the mucus layer [121], but it would even be more interesting if in this way also the personal microbiome could be taken into account.

As mentioned, developments in the field of sensors go very fast, and that is essential to bring more complex systems as the digestive chips and organs on a chip to the next level. In pharma, great progress is made. For example, some organs on a chip are commercially available. We foresee that also in the food field these systems will find their place, most probably first to detect components and microorganisms with great resolution. For this, concentration of samples is a field that needs to be co-designed, since some components are present in such low concentrations (e.g., allergens, pathogens) that in the volumes typically used in microfluidic device detection would be very cumbersome and mostly not possible due to statistical considerations. What we are most enthusiastic about is the potential link this technology may establish between composition/structure of food and the effects in humans, even at individual level, which would bring the fields of nutrition and food technology together at unprecedented level.

\section{Concluding Remarks}

To achieve sustainable healthy food products, microfluidic insights can be of great relevance. In this review/opinion paper, we discuss this extensively for isolation of components and for emulsion formation. At small scale, it has been demonstrated that both processes can be achieved at much lower energy input as in classic technology. Furthermore, we have given examples of how microfluidic devices have been instrumental in quantifying clogging of pores and emulsifier adsorption. Given the similarity in time scales at which processes can be investigated, the findings obtained through microfluidic 
Fig. 14 Various organs on chips can be used to evaluate the overall effect in humans based on various readout techniques ([122]; published open access)
Human-on-a-Chip

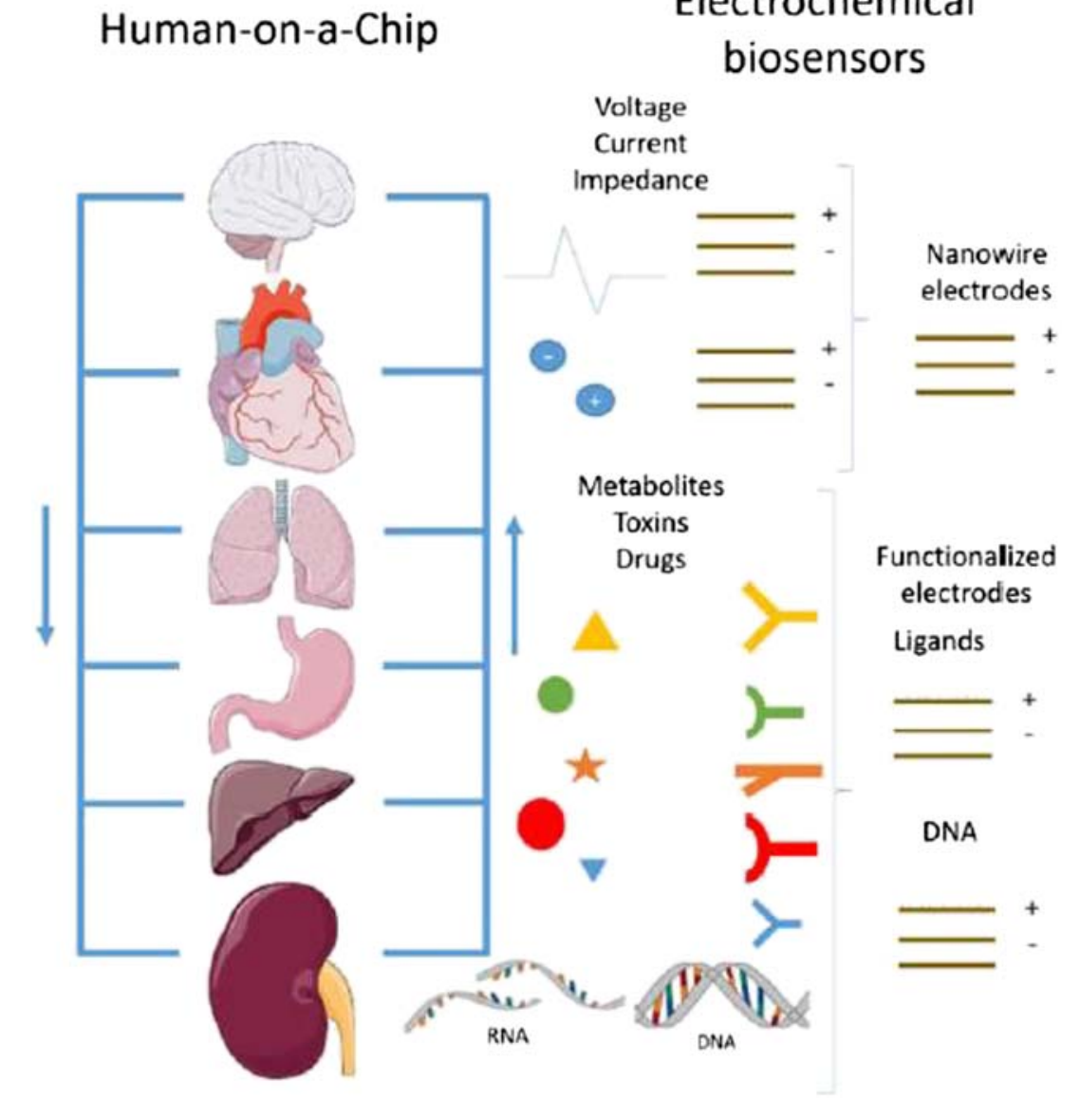

Electrochemical biosensors

(r)

observation are also expected to be immediately relevant for processes as currently carried out on large scale.

The developments currently taking place in related fields make us enthusiastic about the options they may give in the field of food. Most importantly, we think that it will be possible to link food ingredient functionality and food structure to effects taking place during digestion in the near future. But that will not be the end point for microfluidic techniques. Also effects as they take place in cells can be monitored through organs on a chip methods, which will be instrumental in including nutritional effects in food design. In that respect, the many insights presented here are only the tip of the proverbial iceberg of options that the technology has on offer and that hold the potential to revolutionize the way that we design the sustainable, healthy foods of the future.

Open Access This article is licensed under a Creative Commons Attribution 4.0 International License, which permits use, sharing, adaptation, distribution and reproduction in any medium or format, as long as you give appropriate credit to the original author(s) and the source, provide a link to the Creative Commons licence, and indicate if changes were made. The images or other third party material in this article are included in the article's Creative Commons licence, unless indicated otherwise in a credit line to the material. If material is not included in the article's
Creative Commons licence and your intended use is not permitted by statutory regulation or exceeds the permitted use, you will need to obtain permission directly from the copyright holder. To view a copy of this licence, visit http://creativecommons.org/licenses/by/4.0/.

\section{References}

1. Agboola SO, Dalgleish DG (1996) Enzymatic hydrolysis of milk proteins used for emulsion formation. 1. Kinetics of protein breakdown and storage stability of the emulsions. J Agric Food Chem 44:3631-3636. https://doi.org/10.1021/jf9602840

2. Altena FW, Belfort G (1984) Lateral migration of spherical particles in porous flow channels: application to membrane filtration. Chem Eng Sci 39(2):343-355. https://doi.org/10.1016/00092509(84)80033-0

3. Amstad E, Chemama M, Eggersdorfer M, Arriaga LR, Brenner M, Weitz DA (2016) Robust scalable high throughput production of monodisperse drops. Lab Chip 16:4163-4172. https://doi.org/ 10.1039/C6LC01075J

4. Martinez AW, Phillips ST, Butte MJ, G. M. W. (2013) Patterned paper as a platform for inexpensive, low volume, portable bioassays. Angew Chem Int Ed Eng. Author manuscript; available in PMC 2013 October 21, 2007 46(8):1318-1320. https://doi.org/10. 1002/anie.200603817.Patterned

5. Anis SF, Hashaikeh R, Hilal N (2019) Reverse osmosis pretreatment technologies and future trends: a comprehensive review. Desalination 452(October 2018):159-195. https://doi.org/10. 1016/j.desal.2018.11.006 
6. Atalay YT, Vermeir S, Witters D, Vergauwe N, Verbruggen B, Verboven P et al (2011) Microfluidic analytical systems for food analysis. Trends Food Sci Technol 22(7):386-404. https://doi.org/ 10.1016/j.tifs.2011.05.001

7. Baret J-C (2012) Surfactants in droplet-based microfluidics. Lab Chip 12(3):422-433. https://doi.org/10.1039/C1LC20582J

8. Be S, Fillaudeau L, Decloux M, Daufin G, \& Carre H (2001) Recent and emerging applications of membrane processes in the food and dairy industry, 79(June)

9. Belfort G, Davis RH, Zydney AL (1994) The behavior of suspensions and macromolecular solutions in cross-flow microfiltration. J Membr Sci 96(1-2):1-58. https://doi.org/10.1016/03767388(94)00119-7

10. Belfort $G$ (1989) Fluid mechanics in membrane filtration: recent developments. J Membr Sci 40(2):123-147. https://doi.org/10. 1016/0376-7388(89)89001-5

11. Berton-Carabin CC, Ropers MH, Genot C (2014) Lipid oxidation in oil-in-water emulsions: involvement of the interfacial layer. Compr Rev Food Sci Food Saf 13(5):945-977 Retrieved from http://edepot.wur.nl/345920

12. Berton-Carabin CC, Schröder A, Rovalino-Cordova A, Schroën K, Sagis L (2016) Protein and lipid oxidation affect the viscoelasticity of whey protein layers at the oil-water interface. Eur J Lipid Sci Technol 118(11):1630-1643. https://doi.org/10.1002/ejlt. 201600066

13. Berton C, Genot C, Ropers M-H (2011) Quantification of unadsorbed protein and surfactant emulsifiers in oil-in-water emulsions. J Colloid Interface Sci 354(2):739-748. https://doi. org/10.1016/j.jcis.2010.11.055

14. Blanpain-Avet P, Doubrovine N, Lafforgue C, Lalande M (1999) The effect of oscillatory flow on crossflow microfiltration of beer in a tubular mineral membrane system - membrane fouling resistance decrease and energetic considerations. J Membr Sci 152(2): 151-174. https://doi.org/10.1016/S0376-7388(98)00214-2

15. Bouhid de Aguiar I, Meireles M, Bouchoux A, Schroën K (2019) Conformational changes influence clogging behavior of micrometer-sized microgels in idealized multiple constrictions. Sci Rep 9(1):1-9. https://doi.org/10.1038/s41598-019-45791-y

16. Bouhid de Aguiar I, Schroën K, Meireles M, Bouchoux A (2018) Compressive resistance of granular-scale microgels: from loose to dense packing. Colloids Surf A Physicochem Eng Asp 553(March):406-416. https://doi.org/10.1016/j.colsurfa.2018.05. 064

17. Brans G, Schroën CGPH, van der Sman RGM, Boom RM (2004) Membrane fractionation of milk: state of the art and challenges. J Membr Sci 243(1-2):263-272. https://doi.org/10.1016/j.memsci. 2004.06.029

18. Bremond N, Bibette J (2012) Exploring emulsion science with microfluidics. Soft Matter 8(41):10549. https://doi.org/10.1039/ c2sm25923k

19. Brosseau Q, Vrignon J, Baret J-C (2014) Microfluidic dynamic interfacial tensiometry ( $\mu$ DIT). Soft Matter 10:3066-3076. https:// doi.org/10.1039/c3sm52543k

20. Charcosset C (2009) Preparation of emulsions and particles by membrane emulsification for the food processing industry. $\mathrm{J}$ Food Eng 92(3):241-249. https://doi.org/10.1016/j.jfoodeng. 2008.11.017

21. Chen GQ, Artemi A, Lee J, Gras SL, Kentish SE (2019) A pilot scale study on the concentration of milk and whey by forward osmosis. Sep Purif Technol 215(January):652-659. https://doi. org/10.1016/j.seppur.2019.01.050

22. Cheng G, Hao SJ, Yu X, Zheng SY (2015) Nanostructured microfluidic digestion system for rapid high-performance proteolysis. Lab Chip 15(3):650-654. https://doi.org/10.1039/ c4lc01165a
23. Chiu SW, Tang KT (2013) Towards a chemiresistive sensorintegrated electronic nose: a review. Sensors (Switzerland) 13. https://doi.org/10.3390/s131014214

24. Corstens MN, Berton-Carabin CC, de Vries R, Troost FJ, Masclee AAM, Schroën K (2017) Food-grade micro-encapsulation systems that may induce satiety via delayed lipolysis: a review. Crit Rev Food Sci Nutr 57(10):2218-2244. https://doi.org/10.1080/ 10408398.2015.1057634

25. Corstens MN, Berton-Carabin CC, Kester A, Fokkink R, van den Broek JM, de Vries R et al (2016) Destabilization of multilayered interfaces in digestive conditions limits their ability to prevent lipolysis in emulsions. Food Struct $\mathrm{x}(\mathrm{x}), \mathrm{x}$

26. Davis R (1992) Modeling of fouling of crossflow microfiltration membranes. Sep Purif Methods (December 2012):75-126. https:// doi.org/10.1080/03602549208021420

27. Davis RH, Sherwood JD (1990) A similarity solution for steadystate crossflow microfiltration. Chem Eng Sci 45(11):3203-3209. https://doi.org/10.1016/0009-2509(90)80212-W

28. Davis R, Leighton D (1987) Shear-induced transport of a particle layer along a porous wall. Chem Eng Sci 42(2):275-281. https:// doi.org/10.1016/0009-2509(87)85057-1

29. Deng B \& Ruiter JDe (2019) Application of microfluidics in the production and

30. Dijkshoorn JP, Schutyser MAI, Wagterveld RM, Schroën CGPH, Boom RM (2017) A comparison of microfiltration and inertiabased microfluidics for large scale suspension separation. Sep Purif Technol 173. https://doi.org/10.1016/j.seppur.2016.09.018

31. Dridi F, Marrakchi M, Gargouri M, Saulnier J, Jaffrezic-Renault N, Lagarde F (2017) Nanomaterial-based electrochemical biosensors for food safety and quality assessment. Nanobiosensors Elsevier Inc. https://doi.org/10.1016/b978-0-12-804301-1.000059

32. Duarte LC, De Carvalho TC, Lobo-Júnior EO, Abdelnur PV, Vaz BG, Coltro WKT (2016) 3D printing of microfluidic devices for paper-assisted direct spray ionization mass spectrometry. Anal Methods 8(3):496-503. https://doi.org/10.1039/c5ay03074a

33. Duffy DC, McDonald JC, Schueller OJA, Whitesides GM (1998) Rapid prototyping of microfluidic systems in poly(dimethylsiloxane). Anal Chem 70(23):4974-4984. https://doi.org/10.1021/ ac980656z

34. Duncan TV (2011) The communication challenges presented by nanofoods. Nat Nanotechnol 6(11):683-688. https://doi.org/10. 1038/nnano.2011.193

35. Evans M, Ratcliffe I, Williams PA (2013) Emulsion stabilisation using polysaccharide-protein complexes. Curr Opin Colloid Interface Sci 18(4):272-282. https://doi.org/10.1016/j.cocis. 2013.04.004

36. Faergemand M, Otte J, Qvist KB (1998) Emulsifying properties of milk proteins cross-linked with microbial transglutaminase. Int Dairy J 8(8):715-723. https://doi.org/10.1016/S0958-6946(98) 00111-3

37. Feng H, Ershov D, Krebs T, Schroen K, Cohen Stuart M, van der Gucht J, Sprakel J (2014) Manipulating and quantifying temperature-triggered coalescence with microcentrifugation. Lab Chip 15(1):188-194. https://doi.org/10.1039/c4lc00773e

38. Field RW, Wu D, Howell JA, Gupta BB (1995) Critical flux concept for microfiltration fouling. J Membr Sci 100(3):259-272. https://doi.org/10.1016/0376-7388(94)00265-Z

39. Fritz PA, Boom RM, Schroen K (2019) Polyelectrolyte-activated carbon composite electrodes for inverted membrane capacitive deionization (iMCDI). Sep Purif Technol 220(March):145-151. https://doi.org/10.1016/j.seppur.2019.03.053

40. Gan Q, Howell J, Field R, England R, Bird M, O'Shaughnessy C, MeKechinie M (2001) Beer clarification by microfiltrationproduct quality control and fractionation of particles and 
macromolecules. J Membr Sci 194(2):185-196. https://doi.org/10. 1016/S0376-7388(01)00515-4

41. Garstecki P, Fuerstman MJ, Stone HA, Whitesides GM (2006) Formation of droplets and bubbles in a microfluidic T-junctionscaling and mechanism of break-up. Lab Chip 6(3):437-446. https://doi.org/10.1039/b510841a

42. Gijsbertsen-Abrahamse AJ, Van Der Padt A, Boom RM (2003) Influence of membrane morphology on pore activation in membrane emulsification. J Membr Sci 217(1-2):141-150. https://doi. org/10.1016/S0376-7388(03)00104-2

43. Gijsbertsen-Abrahamse AJ, Van Der Padt A, Boom RM (2004) Status of cross-flow membrane emulsification and outlook for industrial application. J Membr Sci 230(1-2):149-159. https:// doi.org/10.1016/j.memsci.2003.11.006

44. Güell C, Ferrando M, Schroën K (2016) Membranes for enhanced emulsification processes. Innovative Food Processing Technologies: Extraction, Separation, Component Modification and Process Intensification. https://doi.org/10.1016/B978-0-08100294-0.00017-1

45. Güell C, Ferrando M, Trentin A, Schroën K (2017) Apparent interfacial tension effects in protein stabilized emulsions prepared with microstructured systems. Membranes 7(2). https://doi.org/10. 3390/membranes 7020019

46. Hausmann A, Sanciolo P, Vasiljevic T, Weeks M, Schroën K, Gray S, Duke M (2013) Fouling mechanisms of dairy streams during membrane distillation. J Membr Sci 441. https://doi.org/10.1016/j. memsci.2013.03.043

47. Hausmann A, Sanciolo P, Vasiljevic T, Weeks M, Schroën K, Gray S, Duke M (2013) Fouling of dairy components on hydrophobic polytetrafluoroethylene (PTFE) membranes for membrane distillation. J Membr Sci 442. https://doi.org/10.1016/j.memsci.2013. 03.057

48. Heising JK (2014) Intelligent packaging for monitoring food quality: a case study on fresh fish, 172. Retrieved from http://library. wur.nl/WebQuery/wurpubs/fulltext/298571\#page=63

49. Hinderink EBA, Münch K, Sagis L, Schroën K, Berton-Carabin CC (2019) Synergistic stabilisation of emulsions by blends of dairy and soluble pea proteins: contribution of the interfacial composition. Food Hydrocoll 97. https://doi.org/10.1016/j.foodhyd. 2019.105206

50. Hinderink EBA, Kaade W, Sagis L, Schroën K, Berton-Carabin CC (2020) Microfluidic investigation of the coalescence susceptibility of pea protein-stabilised emulsions: effect of protein oxidation level. Food Hydrocoll 102. https://doi.org/10.1016/j.foodhyd. 2019.105610

51. Muthukumarappan CM (2013) Application of membrane separation technology for developing novel dairy food ingredients. $\mathrm{J}$ Food Process Technol 04(09). https://doi.org/10.4172/21577110.1000269

52. Kant K, Shahbazi MA, Dave VP, Ngo TA, Chidambara VA, Than LQ, Bang DD, Wolff A (2018) Microfluidic devices for sample preparation and rapid detection of foodborne pathogens. Biotechnol Adv 36(4):1003-1024. https://doi.org/10.1016/j. biotechadv.2018.03.002

53. Kobayashi I, Neves MA (2015) Engineering aspects of food emulsification and homogenization

54. Kobayashi I, Neves MA, Uemura K, Nakajima M (2011) Production characteristics of uniform large soybean oil droplets by microchannel emulsification using asymmetric through-holes. Procedia Food Sci 1(Icef 11):123-130. https://doi.org/10.1016/j. profoo.2011.09.020

55. Kobayashi I, Takano T, Maeda R, Wada Y, Uemura K, Nakajima M (2008) Straight-through microchannel devices for generating monodisperse emulsion droplets several microns in size. Microfluid Nanofluid 4(3):167-177. https://doi.org/10.1007/ s10404-007-0167-2
56. Krebs T, Ershov D, Schroen CGPH, Boom RM (2013) Coalescence and compression in centrifuged emulsions studied with in situ optical microscopy. Soft Matter 9(15). https://doi. org/10.1039/c3sm27850f

57. Krebs T, Schroen K, Boom R (2012) A microfluidic method to study demulsification kinetics. Lab Chip 12(6):1060-1070. https://doi.org/10.1039/c2lc20930f

58. Krebs T, Schroën K, Boom R (2012) Coalescence dynamics of surfactant-stabilized emulsions studied with microfluidics. Soft Matter 8(41):10650. https://doi.org/10.1039/c2sm26122g

59. van de Laar T, ten Klooster S, Schroën K, Sprakel J (2016) Transition-state theory predicts clogging at the microscale. Sci Rep 6(April):28450. https://doi.org/10.1038/srep28450

60. van de Laar T, ten Klooster S, Schroën K, Sprakel J, van de Laar T, Higler R et al (2016) Linking findings in microfluidics to membrane emulsification process design: the importance of wettability and component interactions with interfaces. Sci Rep 6(2):86-92. https://doi.org/10.1016/j.seppur.2016.09.018

61. Lakkis J, Villota R (1992) Comparative performance of chemically and enzymatically modified whey proteins. Food Chem 43(2): 93-105. https://doi.org/10.1016/0308-8146(92)90221-M

62. Leighton D, Acrivos A (1987) The shear-induced migration of particles in concentrated suspensions. J Fluid Mech 181(1):415. https://doi.org/10.1017/S0022112087002155

63. Li X, Ballerini DR, Shen W (2012) A perspective on paper-based microfluidics: current status and future trends. Biomicrofluidics 6(1):12-14. https://doi.org/10.1063/1.3687398

64. Low ZX, Chua YT, Ray BM, Mattia D, Metcalfe IS, Patterson DA (2017) Perspective on 3D printing of separation membranes and comparison to related unconventional fabrication techniques. J Membr Sci 523(October):596-613. https://doi.org/10.1016/j. memsci.2016.10.006

65. Saboyainsta LV, Maubois J-L (2000) Current developments of microfiltration technology in the dairy industry. Lait 80(6):541553. https://doi.org/10.1051/lait:2000144

66. Lyon MK, Leal LG (1998) An experimental study of the motion of concentrated suspensions in two-dimensional channel flow. Part 1. Monodisperse systems. J Fluid Mech 363:25-56. https://doi.org/ 10.1017/S0022112098008817

67. Maan AA, Schroën CGPH, Boom RM (2011) Spontaneous droplet formation techniques for monodisperse emulsions preparation - perspectives for food applications. J Food Eng 107(3-4):334-346 Retrieved from http://edepot.wur.nl/176434

68. Martinez AW, Phillips ST, Butte MJ, Whitesides GM (2007) Patterned paper as a platform for inexpensive, low-volume, portable bioassays. Angew Chem Int Ed 46(8):1318. https://doi.org/ 10.1002/anie.200603817

69. Martinez AW, Phillips ST, Whitesides GM (2008) Threedimensional microfluidic devices fabricated in layered paper and tape. Proc Natl Acad Sci U S A 105(50):19606-19611. https://doi. org/10.1073/pnas.0810903105

70. Marze S (2013) Bioaccessibility of nutrients and micronutrients from dispersed food systems: impact of the multiscale bulk and interfacial structures. Crit Rev Food Sci Nutr 53(1):76-108. https://doi.org/10.1080/10408398.2010.525331

71. Marze S, Algaba H, Marquis M (2014) A microfluidic device to study the digestion of trapped lipid droplets. Food Funct 5(7): 1481-1488. https://doi.org/10.1039/c4fo00010b

72. Marze S, Meynier A, Anton M (2013) In vitro digestion of fish oils rich in n-3 polyunsaturated fatty acids studied in emulsion and at the oil-water interface. Food Funct 4(2):231-239. https://doi. org $110.1039 / \mathrm{c} 2$ fo30165b

73. Meng X, Kim S, Puligundla P, Ko S (2014) Carbon dioxide and oxygen gas sensors-possible application for monitoring quality, freshness, and safety of agricultural and food products with emphasis on importance of analytical signals and their 
transformation. J Korean Soc Appl Biol Chem 57(6):723-733. https://doi.org/10.1007/s13765-014-4180-3

74. Mihindukulasuriya SDF, Lim LT (2014) Nanotechnology development in food packaging: a review. Trends Food Sci Technol 40(2):149-167. https://doi.org/10.1016/j.tifs.2014.09.009

75. Mirmoghtadaie L, Shojaee Aliabadi S, Hosseini SM (2016) Recent approaches in physical modification of protein functionality. Food Chem 199:619-627. https://doi.org/10.1016/j. foodchem.2015.12.067

76. Moiré M, Peysson Y, Herzhaft B, Pannacci N, Gallaire F, Augello L, Dalmazzone C, Colin A (2017) Ultralow interfacial tension measurement through jetting/dripping transition. Langmuir 33(10):2531-2540. https://doi.org/10.1021/acs.langmuir.7b00076

77. Muijlwijk K, Colijn I, Harsono H, Krebs T, Berton-Carabin C, Schroën K (2017) Coalescence of protein-stabilised emulsions studied with microfluidics. Food Hydrocoll 70. https://doi.org/ 10.1016/j.foodhyd.2017.03.031

78. Muijlwijk K, Hinderink E, Ershov D, Berton-Carabin C, Schroën $\mathrm{K}$ (2016) Interfacial tension measured at high expansion rates and within milliseconds using microfluidics. J Colloid Interface Sci: 470. https://doi.org/10.1016/j.jcis.2016.02.041

79. Muijlwijk K, Huang W, Vuist J-E, Berton-Carabin C, Schroën K (2016) Convective mass transport dominates surfactant adsorption in a microfluidic Y-junction. Soft Matter 12(44):9025-9029. https://doi.org/10.1039/c6sm01677d

80. Muijlwijk K, Krebs T, Schroen CGPH, Carabin-Berton CC (2013) Microfluidic tools to study stability of protein-stabilised emulsions and foams. Paderborn, Germany

81. Muijlwijk K (2017) Microfluidic methods to study emulsion formation. 10.18174/403476

82. Muijlwijk K, Hinderink E, Ershov D, Berton-Carabin C, Schroen $\mathrm{K}$ (2016) Interfacial tension measured at high expansion rates and within milliseconds using microfluidics. J Colloid Interface Sci 470:71-79. https://doi.org/10.1016/j.jcis.2016.02.041

83. Narsaiah K, Jha SN, Bhardwaj R, Sharma R, Kumar R (2012) Optical biosensors for food quality and safety assurance - a review. J Food Sci Technol 49(4):383-406. https://doi.org/10. 1007/s13197-011-0437-6

84. Nazir A, Schroën K, Boom R (2010) Premix emulsification: a review. J Membr Sci 362(1-2). https://doi.org/10.1016/j.memsci. 2010.06.044

85. Nazir A, Schroën CGPH, Boom RM (2011) High-throughput premix membrane emulsification using nickel sieves having straightthrough por, Zurich, Switzerland Retrieved from http://edepot. wur.nl $/ 242213$

86. Nazir A, Boom RM, Schroën K (2013a) Droplet break-up mechanism in premix emulsification using packed beds. Chem Eng Sci: 92. https://doi.org/10.1016/j.ces.2013.01.021

87. Nazir A, Schroën K, Boom R (2013b) The effect of pore geometry on premix membrane emulsification using nickel sieves having uniform pores. Chem Eng Sci 93:173-180. https://doi.org/10. 1016/j.ces.2013.01.029

88. Nisisako T, Torii T (2008) Microfluidic large-scale integration on a chip for mass production of monodisperse droplets and particles. Lab Chip Miniaturisation Chem Biol 8(2):287-293. https://doi. org/10.1039/b713141k

89. Nisisako T, Ando T, Hatsuzawa T (2012) High-volume production of single and compound emulsions in a microfluidic parallelization arrangement coupled with coaxial annular worldto-chip interfaces. Lab Chip Miniaturisation Chem Biol 12(18): 3426-3435. https://doi.org/10.1039/c2lc40245a

90. Noordman TRBO (2002) Membrane filtration for bright beer, an alternative to Kieselguhr filtration. EBC Congress, Cannes, pp 815-822

91. Nopwinyuwong A, Trevanich S, Suppakul P (2010) Development of a novel colorimetric indicator label for monitoring freshness of intermediate-moisture dessert spoilage. Talanta 81(3):1126-1132. https://doi.org/10.1016/j.talanta.2010.02.008

92. Nunes SP, Sougrat R, Hooghan B, Anjum DH, Behzad AR, Zhao L et al (2010) Ultraporous films with uniform nanochannels by block copolymer micelles assembly. Macromolecules 43(19): 8079-8085. https://doi.org/10.1021/ma101531k

93. Ofner A, Moore DG, Rühs PA, Schwendimann P, Eggersdorfer M, Amstad E et al (2017) High-throughput step emulsification for the production of functional materials using a glass microfluidic device. Macromol Chem Phys 218(2):1-10. https://doi.org/10.1002/ macp. 201600472

94. Poyatos-Racionero E, Ros-Lis JV, Vivancos JL, Martínez-Máñez $R$ (2018) Recent advances on intelligent packaging as tools to reduce food waste. J Clean Prod 172:3398-3409. https://doi.org/ 10.1016/j.jclepro.2017.11.075

95. Pugnaloni LA, Dickinson E, Ettelaie R, Mackie AR, Wilde PJ (2004) Competitive adsorption of proteins and low-molecularweight surfactants: computer simulation and microscopic imaging. Adv Colloid Interf Sci 107(1):27-49. https://doi.org/10. 1016/j.cis.2003.08.003

96. Rateni G, Dario P, Cavallo F (2017) Smartphone-based food diagnostic technologies: a review. Sensors (Switzerland) 17(6). https://doi.org/10.3390/s17061453

97. Rayner M (2015) Scales and forces in emulsification. In: Rayner M, Deymek P (eds) Engineering aspects of food emulsification and homogenisation. Taylor \& Francis, pp 3-30

98. Riechers B, Maes F, Akoury E, Semin B, Gruner P, Baret JC (2016) Surfactant adsorption kinetics in microfluidics. Proc Natl Acad Sci U S A 113(41):11465-11470. https://doi.org/10.1073/ pnas. 1604307113

99. Roos YH, Fryer PJ, Knorr D, Schuchmann HP, Schroën K, Schutyser MAI, Trystram G, Windhab EJ (2016) Food engineering at multiple scales: case studies, challenges and the future - a European perspective. Food Eng Rev 8(2):91-115. https://doi.org/ 10.1007/s12393-015-9125-Z

100. Roos YH, Fryer PJ, Knorr D, Schuchmann HP, Schroën K, Schutyser MAI et al (2015) Food engineering at multiple scales: case studies, challenges and the future - a European perspective. Food Eng Rev (JUNE):91-115. https://doi.org/10.1007/s12393015-9125-Z

101. Rossier-Miranda FJ, Schroën K, Boom R (2010) Mechanical characterization and ph response of fibril-reinforced microcapsules prepared by layer-by-layer adsorption. Langmuir 26(24):1910619113. https://doi.org/10.1021/la1033542

102. Rossier Miranda FJ, van Dijke KC, Akkermans C, van der Goot AJ, Boom RM, Schroën CGPH (2009) Nano-fibril reinforced food grade microcapsules from uniform emulsion droplets. Papendal, Arnhem, Netherlands

103. Rossier Miranda FJ, Schroën CGPH, Boom RM (2012) Microencapsulation by layer-by-layer adsorption of food-grade materials, FranceParis

104. Rotem A, Abate AR, Utada AS, Van Steijn V, Weitz DA (2012) Drop formation in non-planar microfluidic devices. Lab Chip 12(21):4263-4268. https://doi.org/10.1039/c2lc40546f

105. Sagis LMC, Scholten E (2014) Complex interfaces in food: structure and mechanical properties. Trends Food Sci Technol:1-13. https://doi.org/10.1016/j.tifs.2014.02.009

106. Sahin S, Schroën K (2015) Partitioned EDGE devices for high throughput production of monodisperse emulsion droplets with two distinct sizes. Lab Chip Miniaturisation Chem Biol 15(11). https://doi.org/10.1039/c5lc00379b

107. Sahin S (2016) Upscaling microstructured emulsification devices. Wageningen Univers

108. Sahin S, Bliznyuk O, Rovalino Cordova A, Schroën K (2016) Microfluidic EDGE emulsification: the importance of protein/ interface interactions on droplet formation and pressure stability 
(in preparation). Nat Publ Group (November 2015):2-8. https:// doi.org/10.1038/srep26407

109. Salim A, Lim S (2018) Review of recent metamaterial microfluidic sensors. Sensors (Switzerland) 18(1). https://doi. org/10.3390/s18010232

110. Schröder A, Sprakel J, Schroën K, Spaen JN, Berton-Carabin CC (2018) Coalescence stability of Pickering emulsions produced with lipid particles: a microfluidic study. J Food Eng 234:63-72. https://doi.org/10.1016/j.jfoodeng.2018.04.007

111. Schröder A, Berton-Carabin C, Venema P, Cornacchia L (2017) Interfacial properties of whey protein and whey protein hydrolysates and their influence on $\mathrm{O} / \mathrm{W}$ emulsion stability. Food Hydrocoll 73:129-140. https://doi.org/10.1016/j.foodhyd.2017. 06.001

112. Schroen K, Bliznyuk O, Muijlwijk K, Sahin S, Berton-Carabin CC (2015) Microfluidic emulsification devices: from micrometer insights to large-scale food emulsion production. Curr Opin Food Sci 3:33-40. https://doi.org/10.1016/j.cofs.2014.11.009

113. Schroën K, Ferrando M, de Lamo-Castellví S, Sahin S, Güell C (2016) Linking findings in microfluidics to membrane emulsification process design: the importance of wettability and component interactions with interfaces. Membranes 6(2):26. https://doi.org/ 10.3390/membranes6020026

114. Schroën K, Van Dinther AMC, Bogale S, Vollebregt M, Brans G, Boom RM (2010) Membrane processes for dairy fractionation. Membr Technol 3. https://doi.org/10.1002/9783527631384.ch2

115. Schroën K, van Dinther A, Stockmann R (2017) Particle migration in laminar shear fields: a new basis for large scale separation technology? Sep Purif Technol 174. https://doi.org/10.1016/j.seppur. 2016.10.057

116. Schultz S, Wagner G, Urban K, Ulrich J (2004) High-pressure homogenization as a process for emulsion formation. Chem Eng Technol 27(4):361-368. https://doi.org/10.1002/ceat.200406111

117. Segre G, Silberberg A (1962) Behaviour of macroscopic rigid spheres in Poiseuille flow part 1. Determination of local concentration by statistical analysis of particle passages through crossed light beams. J Fluid Mech 14(01):115-135. https://doi.org/10. 1017/S002211206200110X

118. Segre G, Silberberg A (1962) Behaviour of macroscopic rigid spheres in Poiseuille flow part 2. Experimental results and interpretation. J Fluid Mech 14(01):136-157. https://doi.org/10.1017/ S0022112062001111

119. Sharma S, Johnson R, Desai T (2003) Ultrathin poly (ethylene glycol) films for silicon-based microdevices. Appl Surf Sci 206: 218-229

120. Skhiri Y, Gruner P, Semin B, Brosseau Q, Pekin D, Mazutis L et al (2012) Dynamics of molecular transport by surfactants in emulsions. Soft Matter 8(41):10618. https://doi.org/10.1039/ c2sm25934f

121. Sontheimer-phelps A, Chou DB, Tovaglieri A, Ferrante TC, Duckworth T, Fadel C, ... Jalili-firoozinezhad S (2019) Human colon-on-a-chip enables continuous in vitro analysis of colon mucus layer accumulation and physiology Short Title : Probing intestinal mucus physiology with a colon-on-a-chip

122. Sosa-Hernández JE, Villalba-Rodríguez AM, Romero-Castillo KD, Aguilar-Aguila-Isaías MA, García-Reyes IE, HernándezAntonio A et al (2018) Organs-on-a-chip module: a review from the development and applications perspective. Micromachines 9(10). https://doi.org/10.3390/mi9100536

123. Stang M, Schuchmann H, Schubert H (2001) Emulsification in high-pressure homogenizers. Eng Life Sci 1(4):151. https://doi. org/10.1002/1618-2863(200110)1:4<151::AID-ELSC151>3.0. $\mathrm{CO} ; 2-\mathrm{D}$

124. Steegmans MLJ, Warmerdam A, Schroen KGPH, Boom RM (2009) Dynamic interfacial tension measurements with microfluidic Y-junctions. Langmuir 25(17):9751-9758. https:// doi.org/10.1021/la901103r

125. Sugiura S, Nakajima M, Iwamoto S, Langmuir MS (2001) Interfacial tension driven monodispersed droplet formation from microfabricated channel array. Langmuir 17(18):5562-5566

126. Van De Laar T, Schroen K, Sprakel J (2015) Cooperativity and segregation in confined flows of soft binary glasses. Phys Rev E Stat Nonlinear Soft Matter Phys 92(2):1-8. https://doi.org/10. 1103/PhysRevE.92.022308

127. Van De Laar T, Ten Klooster S, Schroën K, Sprakel J (2016) Transition-state theory predicts clogging at the microscale. Sci Rep 6:1-8. https://doi.org/10.1038/srep28450

128. Van Den Berg A, Mummery CL, Passier R, Van der Meer AD (2019) Personalised organs-on-chips: functional testing for precision medicine. Lab Chip 19(2):198-205. https://doi.org/10.1039/ c81c00827b

129. Van Der Graaf S, Schroën CGPH, Van Der Sman RGM, Boom RM (2004) Influence of dynamic interfacial tension on droplet formation during membrane emulsification. J Colloid Interface Sci 277(2):456-463. https://doi.org/10.1016/j.jcis.2004.04.033

130. van der Zwan E, Schroën K, Boom R (2009) Premix membrane emulsification by using a packed layer of glass beads. IFAC Proc Vol (IFAC-PapersOnline) 7(PART 1):405-410. https://doi.org/10. 1002/aic

131. Van Dijke K, Veldhuis G, Schroën K, Boom R (2009) Parallelized edge-based droplet generation (EDGE) devices. Lab Chip Miniaturisation Chem Biol 9(19). https://doi.org/10.1039/ b906098g

132. van Dijke KC, Veldhuis G, Schroën K, Boom RM (2010) Simultaneous formation of many droplets in a single microfluidic droplet formation unit. AICHE J 56(3). https://doi.org/10.1002/ aic. 11990

133. van Dijke KC, Schroën K, van der Padt A, Boom R (2010) EDGE emulsification for food-grade dispersions. J Food Eng 97(3):348 354. https://doi.org/10.1016/j.jfoodeng.2009.10.028

134. van Dinther AMC (2012) Flow-induced praticle migration to improve membrane microfiltration. Wageningen University, the Netherlands

135. Van Dinther AMC, Schroën CGPH, Boom RM (2011) High-flux membrane separation using fluid skimming dominated convective fluid flow. J Membr Sci 371(1-2):20-27. https://doi.org/10.1016/ j.memsci.2011.01.013

136. Van Dinther AMC, Schroen CGPH, Boom RM (2013a) Separation process for very concentrated emulsions and suspensions in the food industry. Innov Food Sci Emerg Technol 18: 177-182. https://doi.org/10.1016/j.ifset.2012.12.007

137. Van Dinther AMC, Schroën CGPH, Boom RM (2013b) Particle migration leads to deposition-free fractionation. J Membr Sci 440. https://doi.org/10.1016/j.memsci.2013.03.050

138. Van Dinther AMC, Schroën CGPH, Imhof A, Vollebregt HM, Boom RM (2013c) Flow-induced particle migration in microchannels for improved microfiltration processes. Microfluid Nanofluid 15(4):451-465. https://doi.org/10.1007/ s10404-013-1158-0

139. Van Zwieten R, Van De Laar T, Sprakel J, Schroën K (2018) From cooperative to uncorrelated clogging in cross-flow microfluidic membranes. Sci Rep 8(1). https://doi.org/10.1038/s41598-01824088-6

140. Vladisavljevic GT, Kobayashi I, Nakajima M (2012) Production of uniform droplets using membrane, microchannel and microfluidic emulsification devices. Microfluid Nanofluid 13(1): 151-178. https://doi.org/10.1007/s10404-012-0948-0

141. Vogelaar BL, Barsema JN, Van Rijn CJM, Nijdam W, Wessling M (2003) Phase separation micromoldingĐPS $1 \mathrm{M} * *$. (16):13851389. https://doi.org/10.1002/adma.200304949 
142. Vogelaar L, Lammertink RGH, Barsema JN, Nijdam W, BolhuisVersteeg LAM, Van Rijn CJM, Wessling M (2005) Phase separation micromolding: a new generic approach for microstructuring various materials. Small 1(6):645-655. https://doi.org/10.1002/ sml1.200400128

143. Vollebregt HM, van der Sman RGM, Boom RM (2010) Suspension flow modelling in particle migration and microfiltration. Soft Matter 6(24):6052. https://doi.org/10.1039/ c0sm00217h

144. Vollebregt HM, van der Sman RGM, Boom RM (2012) Model for particle migration in bidisperse suspensions by use of effective temperature. Faraday Discuss 158:89. https://doi.org/10.1039/ c2fd20035j

145. Wang K, Lu YC, Xu JH, Luo GS (2009) Determination of dynamic interfacial tension and its effect on droplet formation in the Tshaped microdispersion process. Langmuir 25(4):2153-2158. https://doi.org/10.1021/la803049s

146. Wang H, Liu Y, Li M, Huang H, Xu HM, Hong RJ, Shen H (2010) Multifunctional $\mathrm{TiO} 2$ nanowires-modified nanoparticles bilayer film for 3D dye-sensitized solar cells. Optoelectron Adv Mater Rapid Commun 4(8):1166-1169. https://doi.org/10.1039/ b000000x

147. Wang X, Riaud A, Wang K, Luo G (2014) Pressure drop-based determination of dynamic interfacial tension of droplet generation process in T-junction microchannel. Microfluid Nanofluid 18(3): 503-512. https://doi.org/10.1007/s10404-014-1449-0

148. Wang Y-N, Wang R, Li W, Tang CY (2017) Whey recovery using forward osmosis - evaluating the factors limiting the flux performance. J Membr Sci 533:179-189. https://doi.org/10.1016/J. MEMSCI.2017.03.047

149. Wang YN, Wang R, Li W, Tang CY, Chen GQ, Artemi A et al (2019) Microfiltration, ultrafiltration, nanofiltration, reverse osmosis, and forward osmosis. Sustain Mater Technol 122(October 2018):652-659. https://doi.org/10.1016/j.susmat.2016.02.001

150. Warriner K, Reddy SM, Namvar A, Neethirajan S (2014) Developments in nanoparticles for use in biosensors to assess food safety and quality. Trends Food Sci Technol 40(2):183199. https://doi.org/10.1016/j.tifs.2014.07.008

151. Weng X, Neethirajan S (2017) Ensuring food safety: quality monitoring using microfluidics. Trends Food Sci Technol 65:10-22. https://doi.org/10.1016/J.TIFS.2017.04.015

152. Xu JH, Dong PF, Zhao H, Tostado CP, Luo GS (2012) The dynamic effects of surfactants on droplet formation in coaxial microfluidic devices. Langmuir 28(25):9250-9258. https://doi. org/10.1021/la301363d

153. Zhang Y, Zuo P, Ye BC (2015) A low-cost and simple paper-based microfluidic device for simultaneous multiplex determination of different types of chemical contaminants in food. Biosens Bioelectron 68:14-19. https://doi.org/10.1016/j.bios.2014.12.042

154. van der Zwan EA, Schroën CGPH, van Dijke KC, Boom RM (2006) Visualization of droplet break-up in pre-mix membrane emulsification using microfluidic devices. Colloids Surf A Physicochem Eng Asp 277(1-3):223-229 Retrieved from http:// edepot.wur.n1/41808

\section{Internet sources}

https://sustainabledevelopment.un.org/. Access date: December 2019 https://www.aquamarijn.nl/. Access date: December 2019 https://www.vecoprecision.com/. Access date: December 2019 https:/www.nanopack.eu/2018/02/09/future-packaging-already/ intelligent-packaging/. Access date: December 2019

https://www.wur.nl/en/Dossiers/file/Dossier-Food-waste.htm. Access date: December 2019

Publisher's Note Springer Nature remains neutral with regard to jurisdictional claims in published maps and institutional affiliations. 